\title{
An international investigation into student concerns regarding transition into higher education computing.
}

\author{
ZARB, M., ALSHAIGY, B., BOUVIER, D., GLASSEY, R., HUGHES, J., \\ RIEDESEL, C.
}

(C) The Authors 2018. This is the author's version of the work. It is posted here for your personal use. Not for redistribution. The definitive Version of Record was published in Proceedings of the 23rd Annual ACM Conference on Innovation and Technology in Computer Science Education (ITiCSE 2018), http://dx.doi.org/10.1145/3293881.3295780. 


\section{An International Investigation into Student Concerns regarding Transition into Higher Education Computing}

\author{
Mark Zarb* \\ Robert Gordon University \\ Aberdeen, UK \\ m.zarb@rgu.ac.uk
}

Richard Glassey

KTH Royal Institute of Technology

Stockholm, Sweden

glassey@kth.se

\author{
Bedour Alshaigy \\ Oxford-Brookes University \\ Oxford, UK \\ 12012361@brookes.ac.uk
}

\author{
Janet Hughes \\ The Open University \\ Edinburgh, UK \\ janet.hughes@open.ac.uk
}

\author{
Dennis Bouvier \\ Southern Illinois University \\ Edwardsville \\ Edwardsville, IL, USA \\ djb@acm.org \\ Charles Riedesel \\ University of Nebraska \\ Lincoln, NE, USA \\ chuckr@unl.edu
}

\begin{abstract}
The experience of transitioning into and starting higher education is very much an individual one, with some applicants viewing the prospect of higher education as an unknown entity. For those who are first in their family or community to consider higher education, it can seem to be an "alien environment". This is just one of the issues that lead to applicants experiencing levels of concern when considering a transition into higher education. This international working group aims to answer the following research question: "What are the concerns that computing students have with regards to their transition into higher education?" A survey was administered and the results evaluated.
\end{abstract}

\section{CCS CONCEPTS}

- Applied computing $\rightarrow$ Education; $\bullet$ Social and professional topics $\rightarrow$ CS1;

\section{KEYWORDS}

concerns, transition, CS1, applicants, higher education

\section{ACM Reference Format:}

Mark Zarb, Bedour Alshaigy, Dennis Bouvier, Richard Glassey, Janet Hughes, and Charles Riedesel. 2018. An International Investigation into Student Concerns regarding Transition into Higher Education Computing. In Proceedings of 23rd Annual ACM Conference on Innovation and Technology in Computer Science Education (ITiCSE'18). ACM, New York, NY, USA, 23 pages. https://doi.org/10.1145/3197091.3205842

\section{INTRODUCTION}

What do new students miss? Their pet, their family and friends, the food that reminds them of home... the list goes on. But as they start

\section{*Leader}

Permission to make digital or hard copies of part or all of this work for personal o classroom use is granted without fee provided that copies are not made or distributed for profit or commercial advantage and that copies bear this notice and the full citation on the first page. Copyrights for third-party components of this work must be honored. For all other uses, contact the owner/author(s).

ITiCSE'18, July 2-4, 2018, Larnaca, Cyprus

(c) 2018 Copyright held by the owner/author(s)

ACM ISBN 978-1-4503-5707-4/18/07 . \$15.00

https://doi.org/10.1145/3197091.3205842 their new lives, hoping for an education, a sense of purpose and a potential career, these students also have valid worries:

- "Not knowing what I want to do with my life"

• "Money"

- "My ability to obtain student loans... and my ability to pay them off"

- "My issues with procrastination"

- "Making friends because of my shyness"

- "How I will choose my courses and their difficulty"

- "Not enjoying what I am studying and feeling like I am wasting money"

- "Integrating myself properly"

- "Missing my family and friends"

- "Housing and accommodation"

- "Finding a job"

- "Not fitting in, and not being smart enough"

- "Everything"

These concerns are a sample of free text responses to a survey investigating the concerns of computing students transitioning from high school to collegiate life. The responses reflect a broad range of student concerns; some related to loneliness issues that may distract students from their studies, others expressing concern over adequate academic preparation and maturity, and still others dealing with the unknowns of money and career.

The transition into higher education is one that can cause concern across undergraduates in their early years of study. This concern can ripple through the student's academic career and potentially impact their ability or willingness to stay on the course, thereby affecting retention rates.

Prior work in this area $[42,49]$ has considered this question from the perspective of a single country, looking at over the concerns of over 700 prospective applicants and CS1 students across Scotland. The consistency reported between relative areas of concern over the years was striking, suggesting that a deeper understanding of these issues might help higher education institutions to better support their incoming students.

The research question that will be answered by this study is: "What are the concerns that computing students have with regards to their transition into higher education?" Answering this question would allow an understanding of whether concerns differ by gender 
or by institution, and for recommendations to be made both for institutions on how to best support their students through this transition, and for students on how to best manage their transition into higher education.

\section{LITERATURE REVIEW}

Previous research tends to follow two dimensions. One is the target population, including high school to higher education (the focus of this paper), community college to college, veterans, and underrepresented groups from high schools. The other dimension is the stage being addressed including K-12, the summer before entering college, and the first year college students.

Much of the research is in the development of programs that address perceived transitional challenges and stresses. Some of the research involves surveys and other data collection on which to perform sophisticated analytics, with the goal of identifying at-risk students for whom intervention can be focused. Included in this section is research pertaining to specifically computer science students along with comparable research of more general engineering/STEM students. Studies cited here draw from a range of samples, including several having a majority of female participants and others that feature different ethnic groups and different ages of students, including those not entering higher education not straight from high school.

\subsection{Issues with Transition to Higher Education}

Broadly similar issues have been raised regularly for almost 20 years [12]. It appears that students' concerns focus upon:

- Money

- Domestic adjustments

- Academic adjustments

- Time management

- Study skills

Earlier work corresponds to more recent summaries, for example by Jindal-Snape and Rienties [24], who identified a range of stresses such as academic, sociocultural and practical/lifestyle. Students' expectations in these areas apparently contribute to these stresses.

2.1.1 Student Expectations. These expectations of higher education are based on the students' internalised images and beliefs about university life. Often there are conflicts between their beliefs and the realities, as reported by e.g. Cook and Leckey [12]. Maunder et al. [30] noted that students often had conflicts between their expectations of university before they started and reality. In their study of psychology students, they found that "several students expected more difficult work and increased pressure, and were surprised that it was not like this". Pleitz et al. surveyed students on an introductory course at a mid-western public institution [35], reporting that "many students are entering higher education with an inaccurate idea of what college life will be like". Their questionnaire focused on student's experiences relating to institutional commitment, goal commitment, social integration, academic integration and financial concerns. Pleitz et al. judge that many students are entering higher education with either unknown or naive expectations, particularly in the academic area but (to a lesser extent) also in the areas of social and institutional expectations.
Similarly, McGhie [31] reported that few students came to university with the 'correct' expectations. In the same paper, McGhie identified two groups of students: group 1 students "experienced difficulty overcoming transition challenges" whilst group 2 students made the transition successfully without failing any course. McGhie identifies students in the second group as having the correct expectations (for example that the university learning environment would be different from the high school experience) and taking responsibility for their own learning as factors in their successful transition to higher education [31].

Cole's [32] summary of nine studies notes that students who enter higher education uncertain about what is expected of them experienced "increased difficulty integrating into higher education and developing an academic identity", thus highlighting the importance of student expectations regarding their first-year experiences. Cole comments upon a connection between student expectations and their successful integration during the first year of higher education: "expectations can inhibit or facilitate successful transition from secondary school to higher education".

2.1.2 Facilitating a Successful Transition. Bowles et al. [9] identified factors that are perceived to be enablers of successful transition to higher education; one set is student-centred (study, effort and culture) and the other set is university-led (orientation, learning at university, facilities and social factors). Few of these more recent studies are specific to computing or computer science, although, in 2003, Lowe and Cook [29] noted that "More students in the Faculties of Science (35\%) and Informatics (34\%), however, experienced more problems with the pace of work than they expected. This is compared with an overall average of $22 \%$ experiencing such difficulties."

2.1.3 Identifying Transition Challenges. McInnis [32] has questioned what researchers should be investigating: "We researchers have not, for example, asked students enough questions about the relative importance of what we have assumed is important in the process of transition from school to university. It might be asked if we are in danger of becoming overly concerned, if not precious, about aspects of the first year experience that are of little consequence to the students themselves."

In light of that challenge to researchers, this paper describes work to discover what are the concerns that computing and computer science students have regarding their transition into higher education. The starting point of this research is the standard set of factors identified as above, including financial, academic, socio/cultural, and practical/lifestyle.

\subsection{Analytics research to identify needs and causes of attrition}

Alkhasawneh [3] looked at the underrepresented population in engineering in general, wanting to identify significant features that impact academic success. Creating a framework was part of the effort. Focus group discussions provided the needed data. The results state that "overall, pre-college preparation and family background were found to be strong predictors of academic success and retention. In addition, freshman year academic performance and GPA are considered strong predictors of student retention. Apparently, 
empowering student with self-motivation has a great influence on student decision to continue in STEM fields."

Barker [5] focused on identifying the factors that most impact student decisions to stay in computing or to leave it. The survey yielded racism/sexism, meaningful/relevant assignments, collaborative learning, teaching assistants, classroom climate, studentstudent interaction, pace/workload/programming experience, and faculty-student interaction as prime factors.

Hutt [23], Aguiar [1], and Ameri [4] all employed analytical techniques to identify at-risk students, based on various academic, demographic, and surveyed data. The processes employed by Hutt and Aguiar are briefly described here:

Hutt [23] used machine learning techniques to take a variety of student and institutional information to predict successful graduation probabilities for students. Using only application data, their random forest models successfully predicted 4-year bachelor's graduation for more than $71 \%$ of the sample.

Abstracting from their main findings: "The models utilized a range of features including socioeconomic factors, academic history, cognitive ability, the high school environment, and indicators of extracurricular participation (that may reflect non-cognitive characteristics). No one set of features outperformed a combination from multiple categories, and the minimal feature set included a combination of socio-demographics, cognitive abilities, and extracurricular and work activities. Incorporating extracurricular engagement and work experiences into the analysis resulted in accurately predicting outcomes for two thirds of the students missed by the more traditional model."

"The model's predictions were still inaccurate for $28 \%$ of the students. In many ways, this is a comforting result because the models only consider data up to high-school. These erroneous predictions confirm that college success does not merely depend on a student's environment, past achievement, and experiences. What students experience and do in college plays a critical role in their success. Simply put, there is no predetermination."

The message from this and related studies is that analytics and frameworks are not sufficient for admission decisions, though they do show promise for advising and interventions.

Aguiar [1] similarly devised a model to predict attrition. Use was made of "ePortfolio" assignments in introductory courses for the purpose of guided reflection. Each contained three sections dealing with aspects of academic engagement. To quote:

(1) Engineering Advising - Required reflection on their engineering major choice and their progress towards engineering skill areas.

(2) Project Updates - Required updates following the completion of each project.

(3) Engineering Exploration - Required reflections after attendance at eight engineering related events that took place outside of the course.

Included with the analysis of these ePortolios was a variety of additional student academic performance and engagement data, as well as demographic data. Testing showed that the inclusion of student academic engagement data significantly improved the accuracy of the system in predicting who would drop out. "We believe this can be used to build early warning systems that would be able to identify at-risk students at very early stages of their academic life, giving educators the opportunity to intervene in a more timely and effective fashion.

Chen [11] looked at STEM populations more broadly, to compare differences in early drop out rate. This is yet another example of developing a framework to identify at-risk students. Among other findings, the problem is indeed more acute in STEM majors.

\subsection{Academic preparation}

Salzman [40] developed an "Instrument to Assess the Effects of PreCollege Engineering Participation on the Experiences of First-Year Engineering Students". Their work began with a study that identified five descriptors of increasing integration through the transition into engineering: Foreclosure, Frustration, Tedium, Connection, and Engaging Others.

Based on these descriptors, it was observed that incoming students did have disparate engineering experiences that could impact first-year success. To address this diversity, they advocate applying multiple targeted strategies ranging from team formation to use of pre-assessment tests that can lead to more effective tailored instruction. In themselves, these strategies may not be sufficient since there are indications that students may respond very differently to their pre-college experiences. Salzman [40] noted that: "Ultimately, first-year engineering instructors and curriculum developers need to know their students and their experiences, and work with their students to create educational activities that are meaningful for the students and promote their continuing development as engineers." Nonetheless, an encouragement towards multiple strategies resonates with findings from a number of earlier studies that focused upon the need to broaden participation in computing education.

2.3.1 Approaches to focus upon under-represented groups in computing education. Ladner and Vandegrift [26, 27] presented two special issues of the ACM Transaction on Computing Education on Broadening Participation. Each issue identifies a range of approaches taken to address under-representation of certain minority groups, women and people with disabilities. Notable findings include Dahlberg et al.'s [13] three year study of strategies to broaden participation in computing. Finding that under-represented (female and minority) students value the social relevance of computing more than majority students, the authors note the importance of incorporating civic engagement and community service into courses. This corresponds to earlier reports e.g. from Guzdial et al. [21] who found that female students were more likely than male students to place importance on communal career characteristics; female students and black students were more likely than male students and white students to choose their major/minor because of an interest in helping people or society (rather than an interest in games, problem solving or programming). Interestingly, Guzdial et al. [21] also found that for under-represented minorities, "encouragement mattered more than ability in terms of in terms of how satisfied they are with computing, how likely they are to complete their computing major/minor, and how likely they are to pursue a career in computing."

Eglash et al. [16] found that performance and attitudes of underrepresented high school students were enhanced by the use of a cultural design approach to teaching computational perspectives 
on fractals. Goode and Margolis [20] describe the positive effects of focussing a precollege curriculum on culturally relevant and meaningful experiences; accompanied by supportive professional development for the high school teachers, they offer their approach as a possible model for others, but note that longitudinal effort is needed. Freeman et al. [18] performed a pilot with a learning environment that ad personal and industry relevance to high schools students, finding that gains in attitude to computing were particularly strong for female and minority students.

Ladner and Vandegrift [26,27] note the importance of an analysis of the perception of students toward computing curriculum and careers, and it is pleasing to note a recurring theme that efforts to increase participation from under-represented groups often benefits the student population more widely. As an example, Rosson et al. [39] found that self-efficacy and social support are predictors of students' orientation towards careers in computing and note that this is not exclusive to female students; they encourage others to develop intervention programs to address these findings.

Whilst a detailed review of work in the area of under-represented groups is outwith the scope of this paper, researchers are directed to the special issues edited by Ladner and Vendegrift $[26,27]$ as an excellent introduction to relatively recent work in this area.

2.3.2 Programs and tools to address stresses among new students. Smith [43] considers an app that would foster communication with family; the intent being to make more accessible an existing support system.

Alkadi [2] describes a student project of building an animated virtual university that, as realistically as possible, allows prospective students to roam around campus, join classes and labs, and in general interact with the environment. This is a particularly creative way of addressing the orientation and expectation concerns of incoming students while simultaneously providing an inspiring service experience for current students.

Rather than simply accept students' "innate" inability to learn, Hoda [22] developed strategies using Learning Edge Momentum (LEM) theory to address student failure. LEM sees the complexity of the interface between previously learned and new material in the field of computer science concepts as requiring careful attention in order to attain ultimate success in programming. Encouraging results have emerged from applying strategies to address the LEM hypothesis to first year students.

Johnson [25] discusses a peer-mentoring program of upper-class students mentoring incoming freshmen engineering students.

Bynum [10] is similar to Johnson in that a strategy that could be described as "IT orientation" for first-time students, including the following list of strategies:

(1) A responsive IT Introduction webpage.

(2) An international student IT session as the internet is considered the main source of communication for them with family and friends.

(3) A digital scavenger hunt.

(4) Student-run dorm sweeps. Part of the orientation is a gamified set of activities built into their LMS.
2.3.3 Attempts to direct students to appropriate majors. Beaubouef [6] examines misconceptions people have regarding computer science. These misconceptions include: the subject being boring with large machines and lots of screens, or that a computer scientist is more of a handyman tinkering with installations, or that self-taught programmers can do the work of professionals and are unaware of the math and science needed, or that computer scientists are mainly "geeks" doing their coding in private. These misconceptions are harmful; they could prevent capable students from even considering the field, or may attract students who are not prepared.

\subsection{Efforts to assist transitioning high school students}

Morioka [33] studied how disadvantaged youth made use of, and might make use of, social media to build images of whom they could become as they make the transition to college. Increasing the visibility of mentors, reducing the perceived risk of judgement, and increasing awareness of social benefits to sharing are seen as goals.

Gleixner [19] describes an intensive multiobjective ten day summer residential program for incoming engineering students to a large university which, among other things, included a community service project that provided benefits of being involved, relevant and bonded.

Dickerson [15] presents a more academically oriented summer program (compared to Gleixner) for incoming underrepresented minority students in engineering intended to improve retention and graduation rates.

Starling [44] worked with 10th-12th graders who were blind, exposing them to engineering experiences, in the hope that those students might become involved in college.

There are several outreach programs that are organized by computing faculties to create an inclusive culture that supports all students. Lewis [28] and Richardson [36] made a number of suggestions for cultivating a supportive culture for computing students, with the aim of improving retention. These included items such as "tell students you believe in their ability to learn", "attribute students' current abilities to their effort and experience and not innate ability", "educate counselors, teachers, parents" and "offer personal encouragement to students".

In 2016, the ACM Education Board formed an ACM Retention Committee to "address the current issue of retention in 4-year, post-secondary CS education programs, specifically of the retention of women and URM students following CS1 and CS2 (where the pipeline is most leaky)". Their objectives was to examine the methods that increase retention and collect data with respect to retention patterns [47].

\subsection{Gender as a factor}

Denner [14] has women talk about experiences being female in college computing classes. Results indicate that not all see their experience through gender lenses. Findings from his research suggest that these students talk about being female in three ways: "1) Being Female is Irrelevant: they don't think about it, or say it doesn't play a role at all; 2) Being Female is a Motivator: being one of few women makes them to want to challenge gender stereotypes; 3 ) 
Being Female is Incompatible with CS: it makes them question their ability or position."

This raises implications of the best ways of dealing with gender. As a solution, Denner suggested "to make gender less salient."

Zundl [50] dealt with living-learning communities and self-efficacy in engineering women. Recognizing the correlation of self-efficacy with persistence and ultimate success, she determined that providing broad early support through community and engineering focused interventions would be most effective: "By adding opportunities for them to meet with successful and established women engineering professionals as well as conduct outreach in engineering during the second-year, we have found all of our students persist from the second to the third year."

Nelson [34] conducted and analyzed a survey to study gender differences in the fear of failure among engineering students. Fears considered included fear of academic failure, loss of interest and uncertainty of the future. The survey reveals that female students may be more sensitive to perceived negative reactions of others to their witnessed failures, and ready to accept the reactions as valid. Unfortunately, concerns about future failures may become reinforced with each such experience.

Roberts [37] surveyed female students who had dropped out in Australian institutions. Recognizing the response rate was quite low, the most dominant reasons related to academic factors and feelings of isolation. The research findings by Blaney [8] are also relevant because it reports on gender differences in self-confidence and self-efficacy in computing. The study specifically considers the perceptions of leadership by undergraduate women in computing and presents three recommendations for addressing resultant issues.

Though the focus of the study is on leadership skills (or confidence in leadership), it finds a significant difference between males and females at the start of the course. Also, there is this finding: "Students left the introductory course feeling less confident about their capacity for computing leadership, relative to their perceptions when they started the course."

\subsection{Additional research}

Rogers [38] looked at the relationship among sleep, stress and technology with university students in general. It appears that students employ their electronics in such a way that they feel they miss about an hour per night of needed sleep. Finding ways of reducing the dependency on these devices may be beneficial for student stress level.

Villa [46] paid special attention to retaining minority computer science students specifically women. She recommended integrating Peer Led Team Learning (PLTL) [41] as a measure to foster constructive relationships between students.

Exter [17] studied the hopes and concerns of new students, parents, and faculty involved with a novel engineering program. Aspects being seen as significant include social/relational, relationship with peers, academic engagement and performance, gender and racial background.

\subsection{Summary}

This previous research reflects a strong interest in identifying and addressing the concerns that may lead to poor performance and attrition. In some cases solutions have been created and used with apparent effectiveness. The work of this working group fills a gap by discovering what concerns and fears are actually being felt by transitioning students. In some cases the stresses are the result of factors that are peripheral to academics, and thus it may be advantageous to try to reduce them. In other cases the stresses, at least at some intensity, are healthy resulting in greater focus and good attention by the students. All deserved to be considered.

\section{METHODOLOGY}

The primary objective of this study is to establish what concerns were reported by an international cohort of students in the 201718 academic session. The analysis of this data will allow for an identification of major issues across this global participant group, and subsequent recommendations for improvement can be made.

\subsection{Survey}

The survey employed in this multi-institutional study (Appendix A) is a slight adaptation of surveys used in previous studies dealing with the ongoing issue of transition into higher education [42, 49]. It consists of 29 Likert-scale questions grouped into the following topic areas:

- Accessibility;

- Course;

- Homesickness;

- Housing;

- Job-related Concerns;

- Lecturers/Professors;

- Money;

- Social Concerns; and

- Study Experience.

There are five response options related to level of concern, from "major concern" to "no concern". A sixth option allowed students to respond "not applicable". In addition, five free-text prompts gave students opportunities to elaborate on a number of items. These are used to give context to the Likert-scale answers, providing additional insights into the quantitative data. Previous work in this area $[42,49]$ recognised that students wanted to express additional thoughts about certain aspects of their entry to higher education; this influenced the choice of free-text prompts, which were:

- I am looking forward to ...

- I will miss ...

- I hope I will find ...

- I worry about ...

- I expect ....

This paper reports an analysis conducted on the quantitative data - the qualitative data will be analysed and reported on in a future publication.

All collected responses were anonymous.

The original survey was designed for use in a Scottish context; thus, adaptations were required to ensure that it worked in this international context. The working group reviewed the original 
questions to ensure appropriateness for a wider audience. This entailed adapting some of the language to be less tailored to a Scottish audience (e.g. using the words 'lecturer' and 'professor', or 'university' and 'college' interchangeably). Further detail was added to certain questions to provide more context, for example, to the various ways a student might choose to finance their study, or to explain what is meant by the term "accessibility".

\subsection{Participation}

Surveys were distributed to first-year computing students attending nine HE institutions, with respondents reporting attending 12 institutions (for example, where a survey was disseminated to a wider group, or where students attended classes in a different institution to the one they felt they were affiliated with). Additionally, the number of responses from two of the institutions were too low to be statistically representative of the student population (approximately 1 response for every 50 invitations). Some responses $(n=13)$ have therefore been excluded from the analysis, and the remaining responses from seven institutions across five countries are reported in this paper.

3.2.1 Institutional Context. Table 1 summarises the seven institutions where data was gathered for this survey. The institution names are not used as identifiers to preserve anonymity. The column labeled 'size' indicates the size of that institution's undergraduate cohort.

Table 1: Institutional Context

\begin{tabular}{c|cccc}
\hline identifier & country & type & size $(\mathrm{ug})$ & context \\
\hline A & Sweden & public & $13 \mathrm{k}$ & campus \\
B & UK & public & $11 \mathrm{k}$ & campus \\
C & UK & public & $14 \mathrm{k}$ & campus \\
D & UK & public & $109 \mathrm{k}$ & distance \\
E & Canada & public & $15 \mathrm{k}$ & campus \\
F & USA & public & $20 \mathrm{k}$ & campus \\
G & Ghana & private & $10 \mathrm{k}$ & campus \\
\hline
\end{tabular}

3.2.2 Data Collection. Data was collected by means of a survey as detailed in section 3.1. All institutions were asked to use the same survey link (hosted on Google Forms) where possible, for ease of collaboration, distribution and viewing of results in this context. The data collection policy for Institution D required the use of in-house systems and therefore in this instance, data was collected separately.

Ethical approval was granted by the Robert Gordon University. Institutions $\mathrm{D}$ and $\mathrm{F}$ were required to apply for further approval through their own internal processes.

- Institution A: Participation was sought during the final mandatory exercise at the end of the semester. The students were informed that the survey was optional and that there was no obligation to participate. As students were divided amongst 12 separate exercise groups running in parallel, the task of distributing the survey was delegated to the teaching assistants responsible for supervising each group and the researcher was not present at any exercise.
- Institution B: Participation was sought after the end of one of the final lectures of the semester. The researcher informed students that the survey would be optional, and that they would be free to leave the room prior to the start of the survey, or during it. Attendance was not monitored for this cohort to preserve full anonymity. The link to the survey was projected at the front of the class, and students were free to decide whether to complete it or not. This was the only data gathering point for this institution.

- Institution C: Participants were voluntarily invited to respond to the survey during a practical lab session two weeks before the end of the semester. In addition, an email was circulated to the whole cohort with a link to the survey for students who did not attend. A final email reminder was sent again after exams.

- Institution D: Participation was sought by way of email invitations to three populations: (i) students who had completed their initial computing module approximately one month earlier; (ii) students who began study of their initial computing module one month earlier; (iii) students who began study of their second computing module approximately two months earlier. Group (i) had completed all the relevant assessments for the module but had not received their module results at that point. In each case, a subset of the available population was identified by the institution's Quality Enhancement and Learning Analytics team, to prevent over-surveying of students. Surveys carried out to satisfy institutional or legal regulation and surveys required by a module team are prioritised over research surveys. The resulting sample comprised approximately $18 \%$ of the available student population for these three groups. Two email reminders were sent out by the survey office on behalf of the research team.

- Institution E: Participation was sought from two separate lab sections, during mandatory lab practicums near the end of the semester. Following the practicum, the researcher informed students that the survey would be optional, and that they would be free to leave the room prior to the start of the survey, or during it. Attendance was not monitored and the researcher left the room, leaving behind only teaching assistants to help with any survey access questions, in order to preserve full anonymity. The link to the survey was projected at the front of the class, and students were free to decide whether or not to complete it. This were the only data gathering points for this institution.

- Institution F: An email containing the survey link was sent to two populations: a mailing list consisting of all freshmen from the fall semester of 2017-18, as well as a list of new students majoring in computer science, computer engineering and software engineering. A number of e-mail reminders were sent to the former population.

- Institution G: Participation was sought using Google Classroom, an online learning management tool. An announcement post was made on the platform, to inform the students that the survey was optional. Responses were not monitored for this cohort to preserve full anonymity. The link to the survey was included in the announcement and students were 
free to decide whether to complete it or not. The announcement encouraged those who read the post to inform others who might have missed it. This was the only data gathering point for this institution.

3.2.3 Participants. Table 2 shows a summary of participant responses split by self-reported gender.

No additional identifying data was collected to preserve anonymity.

The gendered options included "female", "male", "non-traditional", "prefer not to say", "undecided" and "other". The response rates for "female" and "male" generally reflect the gender balance of the student populations in the individual institutions, with the exception of institution $\mathrm{D}$, where women comprise approximately $25 \%$ of the student population but women comprised $41 \%$ of the respondents.

The response rates for participants who identified with genders other than "male" or "female" were low and mostly representative of only one institution. Whilst this data is valuable and can provide context to the concerns experienced by this subset of participants, the numbers are too low to merit inclusion in the more general analysis covered by this paper. This data will therefore be considered for further analysis in a future publication.

\section{RESULTS}

This section will discuss the gathered data, grouped by concern category. Within each section, the gender data will be discussed for the overall category, before reporting individual results per concern. The purpose of this approach is to start understanding any underlying nuances in the data.

\subsection{Housing Concerns}

4.1.1 Introduction. This category consisted of two questions, allowing students to express potential concerns with the items "finding/quality of housing (including additional items such as meal plans etc)" and "having to live with flatmates/roommates". This set of questions was not relevant to Institution $\mathrm{D}$, given its focus upon supported distance and open learning.

4.1.2 Analysis by binary gender. Figure 1 shows the results of the Housing category split by gender. The level of concern expressed by respondents would appear to be mostly the same in terms of having some to major concerns across genders. However, male respondents reported more not applicable and little concern responses than female respondents.

4.1.3 Analysis based on institution. Figure 2 shows the data split by institution for question "Finding/quality of housing (including additional items such as meal plans, etc)". 54\% of participants from Institution $\mathrm{G}$ have reported some major concerns. This is followed by Institutions C and B reporting high concern or greater by $38 \%$ and $35 \%$ respectively. Institutions $\mathrm{F}$ and $\mathrm{E}$ show similar concern levels at $30 \%$ and $26 \%$. Institution $A$ at $23 \%$ show the lowest numbers exhibiting high and major concerns at $11 \%$ and $12 \%$ respectively.

Institutions $\mathrm{C}$ and $\mathrm{B}$ are both student cities containing two universities resulting in a growing housing crisis that drives the cost of rent for students with institution $\mathrm{C}$ in particular located in a city voted the least affordable place to live in the country.

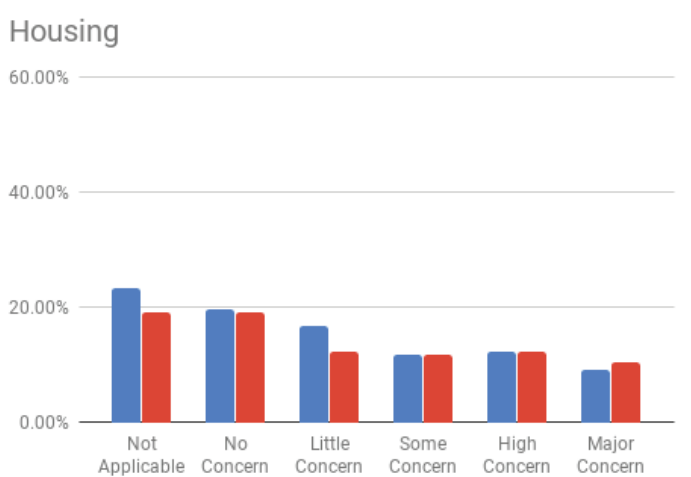

Figure 1: Summary of housing concerns by binary gender

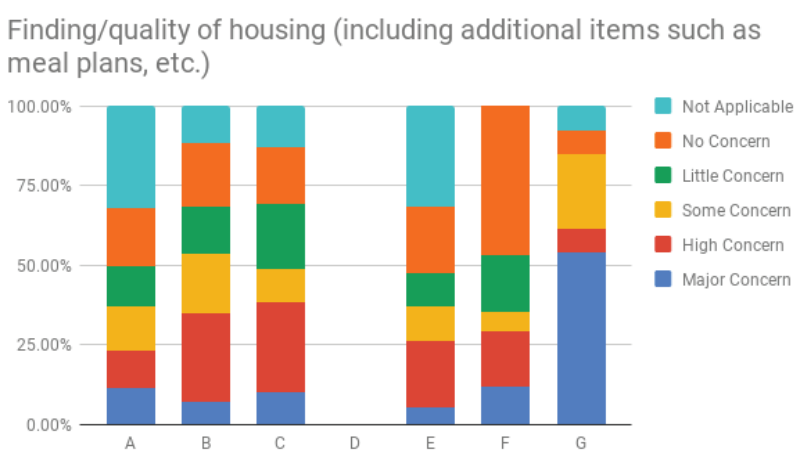

Figure 2: Housing Concern 1(HC1) - Finding/quality of housing

Figure 3 shows the data split by institution for question "Having to live with flatmates/roommates". The highest concern was reported by institution $\mathrm{G}$, with the rest reporting some concern or higher. Institution A has the lowest number of major concern at $5 \%$.

There are three housing options offered at Institution G (oncampus hostel, off-campus hostel, rented apartments), with movement towards attempting to house all first-year students on campus. The breadth of choice here, and the new policy of being housed on campus may be linked with the reports of high concern. The numbers reported by Institution A could be attributed to the fact that Swedish students are more likely to live independently during their studies and do not expect to share their accommodation.

\subsection{Money Concerns}

4.2.1 Introduction. This category consisted of four questions, which focused on the money concerns that students may have regarding general concerns, housing costs, tuition and course fees, and applying for scholarships and funding.

4.2.2 Analysis by binary gender. Figure 4 shows the combined results of the money category split by gender over all four questions within the category. The level of concern remains fairly consistent 
Table 2: Overview of Responses

\begin{tabular}{c|cc|c|ccccc}
\hline identifier & $\mathrm{N}$ & response rate & $\%$ female & $\%$ male & $\%$ non-trad & $\%$ pnts & $\%$ undec & $\%$ other \\
\hline $\mathrm{A}$ & 133 & $>90 \%$ & $23 \%$ & $71 \%$ & $2 \%$ & $2 \%$ & $0 \%$ & $2 \%$ \\
$\mathrm{~B}$ & 69 & $>90 \%$ & $14 \%$ & $86 \%$ & $0 \%$ & $0 \%$ & $0 \%$ & $0 \%$ \\
$\mathrm{C}$ & 39 & $<50 \%$ & $18 \%$ & $79 \%$ & $0 \%$ & $0 \%$ & $3 \%$ & $0 \%$ \\
$\mathrm{D}$ & 61 & $<50 \%$ & $41 \%$ & $59 \%$ & $0 \%$ & $0 \%$ & $0 \%$ & $0 \%$ \\
$\mathrm{E}$ & 18 & $<50 \%$ & $37 \%$ & $63 \%$ & $0 \%$ & $0 \%$ & $0 \%$ & $0 \%$ \\
$\mathrm{~F}$ & 17 & $<50 \%$ & $18 \%$ & $82 \%$ & $0 \%$ & $0 \%$ & $0 \%$ & $0 \%$ \\
$\mathrm{G}$ & 13 & $<50 \%$ & $8 \%$ & $92 \%$ & $0 \%$ & $0 \%$ & $0 \%$ & $0 \%$ \\
\hline total & 351 & & $24 \%$ & $74 \%$ & $1 \%$ & $1 \%$ & $0 \%$ & $1 \%$ \\
\hline
\end{tabular}

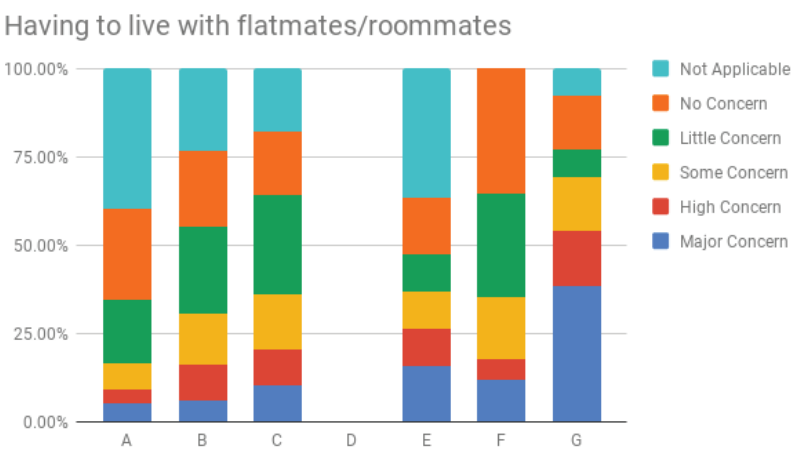

Figure 3: Housing Concern 2 (HC2) - Having to live with flatmates/roommates

between genders. Female students are reporting more high and major concern compared to male students.

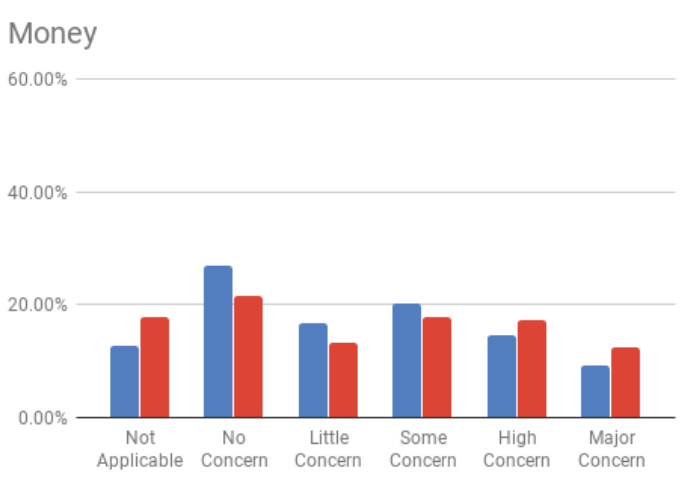

Figure 4: Summary of money concerns by binary gender

4.2.3 Analysis based on institution. Figure 5 shows the data for "general money concerns" split by institution. Institution A shows the lowest concern by far, with respondents reporting high and major concern occupying less than $10 \%$ of the total responses. Institution $\mathrm{F}$ also has less high and major concern, but has a larger amount of responses having some concern. Institutions B to F all

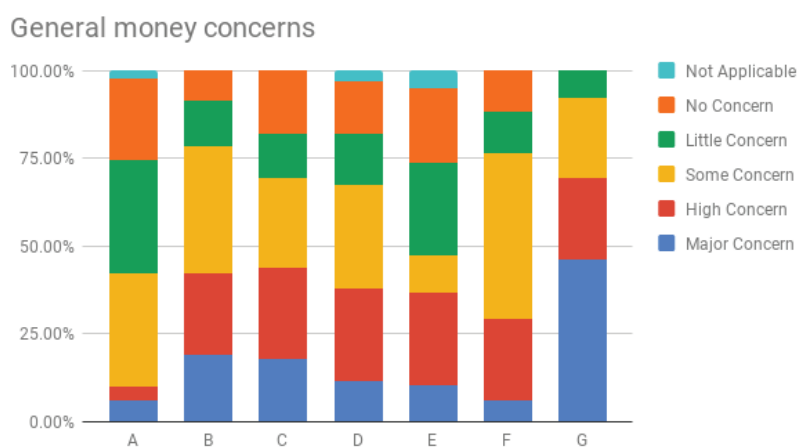

Figure 5: Money Concern 1(MC1) - General money concerns

appear similar, although respondents from Institution D reported less concern which would be expected as many distance learning students studying part-time would already be working. Institution $\mathrm{G}$ reported the most high and major concern. For Institution $\mathrm{G}$, the free-text responses provided indicate that payment of tuition fees was the key issue.

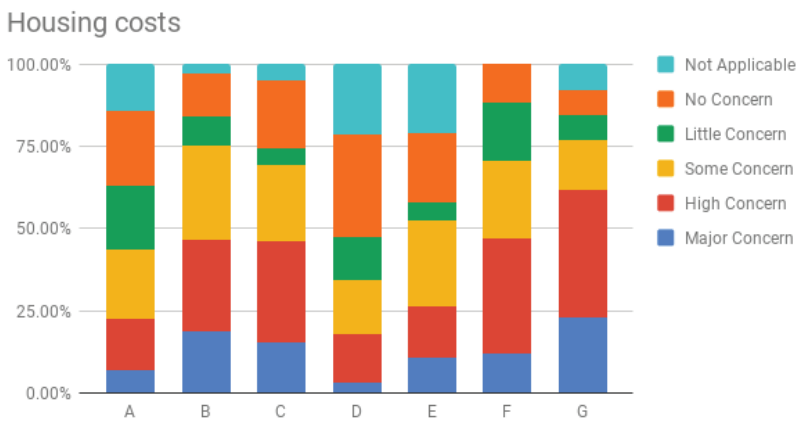

Figure 6: Money Concern 2 (MC2) - Housing costs

In terms of the question regarding "housing costs", Institutions $\mathrm{A}, \mathrm{D}$ and $\mathrm{E}$ were most similar for having lower high and major concerns (see Fig. 6). In particular, it would be expected that because institution $\mathrm{D}$ focuses upon distance learning students, housing costs 
would not be a major concern. The next clear grouping with higher concerns (50\% of high and major concern) consists of Institutions $\mathrm{B}, \mathrm{C}$ and $\mathrm{F}$. Institution $\mathrm{G}$ had the highest amount of high and major concern, with over $50 \%$ respondents indicating this, due to housing in the area being scarce, and relatively expensive.

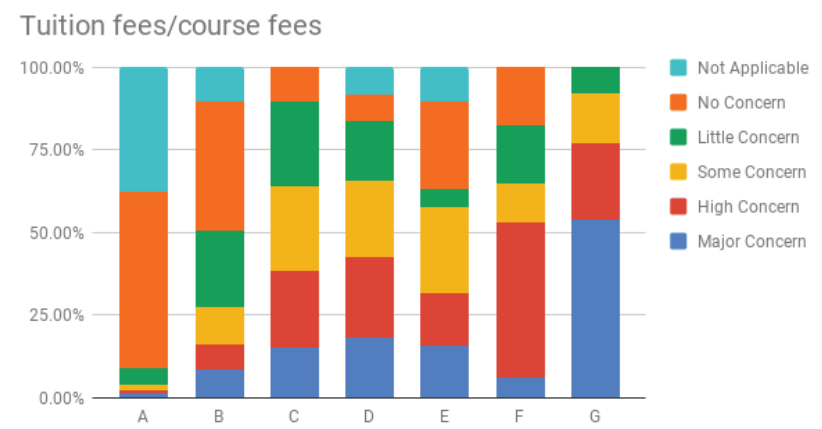

Figure 7: Money Concern 3 (MC3) - Tuition fees/course fees

Figure 7 shows the results from the question on "tuition fees/course fees". Institution A had practically no concerns in this regard, as education is free within Sweden for local students and those coming from any EU/EEA/Nordic country or Switzerland. This also is the case in Institution B, where Scottish and EU students can access higher education without fees. Considering high and major concerns combined, Institutions $\mathrm{F}$ and $\mathrm{G}$ had levels of concern at over $50 \%$, which reflects the general perception of high tuition costs in these countries. Institution G, in particular, reports over $75 \%$ of students with high or major concerns, reflecting the high cost of education in Ghana.

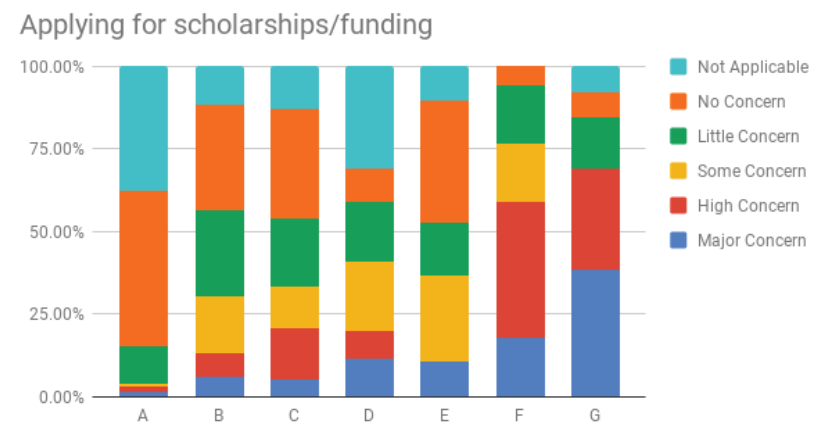

Figure 8: Money Concern 4 - Applying for scholarships/funding

The final question in the Money category concerned "applying for scholarships/funding", as seen in Fig. 8. Institution A clearly shows lower concern (with over $80 \%$ of responses indicating not applicable or no concern). This is explained by the availability and low cost of study loans in Sweden. Institutions B to E all report lower concern overall with applying for scholarships and funding. In contrast, respondents from Institutions $\mathrm{F}$ and $\mathrm{G}$ report reported at least 50\% high and major concern, which resonates with the previous concerns surrounding general money concerns and paying tuition.

\subsection{Job-Related Concerns}

4.3.1 Introduction. This category consisted of two questions, allowing students to express potential concern with the items "finding/keeping a part-time job" and "securing a good job after graduation".

4.3.2 Analysis by binary gender. Figure 9 shows the results of the Job category split by gender. The level of concern seems fairly equal across the board, with approximately $20 \%$ of students reporting no, little, some or high concern, and less reporting in the extremes. Male students do report more "major concern" than female students, however.

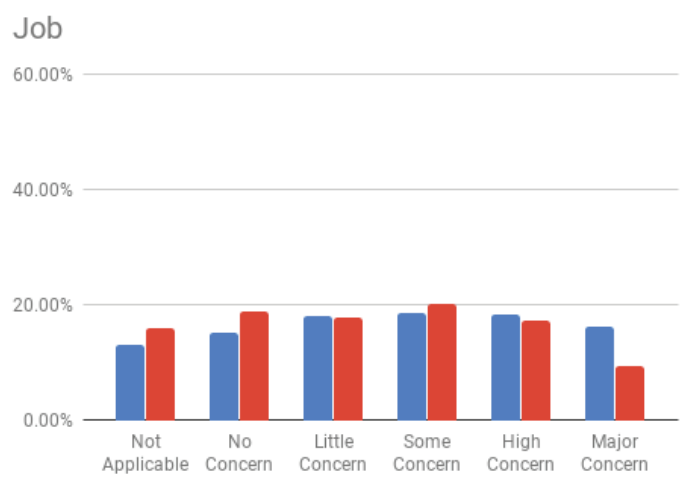

Figure 9: Summary of job-related concerns by binary gender

4.3.3 Analysis based on institution. Figure 10 shows the data split by institution for the question "finding/keeping a part-time job". At least $50 \%$ of participants from Institutions B, E and G have reported some concern or higher, with $84 \%$ of participants from Institution $\mathrm{G}$ in particular reporting high or major concern. These high numbers could be indicative of the fact that the areas surrounding these institutions have limited access to part-time work, or that the students are concerned about juggling part-time work with their studies.

Figure 11 shows the data split by institution for the question "securing a good job after graduation". Most institutions share similar results with roughly $25 \%$ of students indicating major concern, and an additional $25 \%$ indicating high concern. The outliers here are Institutions A and G. With regards to Institution A, there is a big demand in Sweden for IT workers, which students are aware of. Furthermore, the Swedish system allows for more flexibility in their chosen studies and there is less focus on the importance of being employed soon after graduation (when contrasted, for example, to the system in the UK, where students undertaking degree studies are, in some respects, funneled towards employment). Conversely, there is a high level of concern for Institution G, with over $91 \%$ of respondents indicating at least some level of concern. This is attributed to the lack of graduate employment opportunities in Ghana; 


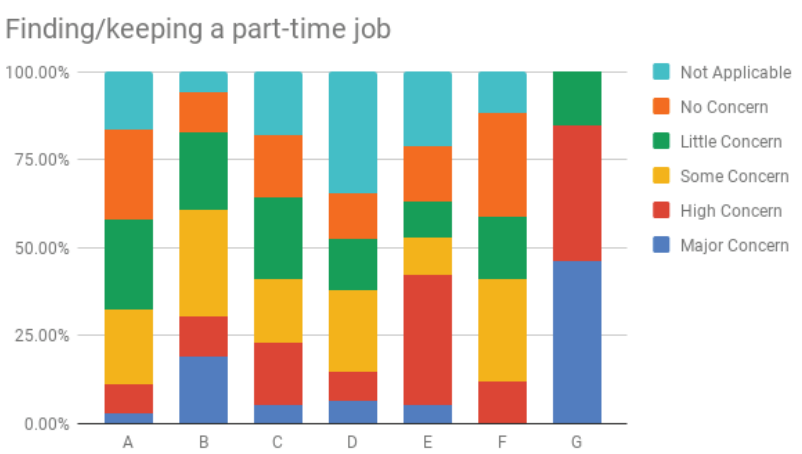

Figure 10: Job-Related Concern 1 (JC1) - Finding/keeping a part-time job

recent statistics show as many as 700,000 unemployed graduates in the country [7].

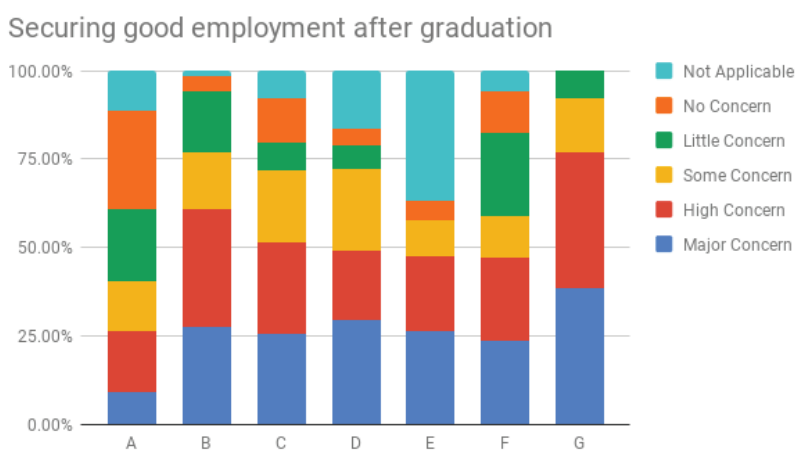

Figure 11: Job-Related Concern 2 (JC2) - Securing a good job after graduation

\subsection{Course Concerns}

4.4.1 Introduction. Course concerns were investigated with seven prompts.

- (CC1) Choosing the right courses

- (CC2) Workload expectation

- (CC3) Managing my time well

- (CC4) Liking the course

- (CC5) Being good at the course

- (CC6) Feeling prepared

- (CC7) The possibility of failing, and any repercussions

Considering all responses, the modal response for two of the seven course concerns (CC7, CC3) are the top two on the list of concerns ranked by modal response (see Table 3). Five of the seven course concerns (CC7, CC3, CC2, CC6, CC5) appear in the top seven on the list of concerns.

4.4.2 Analysis by binary gender. Figure 12 presents the summary of responses to the seven course concerns by binary gender.
This figure shows no key difference between the responses of these two groups. However, when looking into the responses by individual concern, and considering institution, or institution-gender subgroups, a number of differences in responses are found, as will be discussed below.

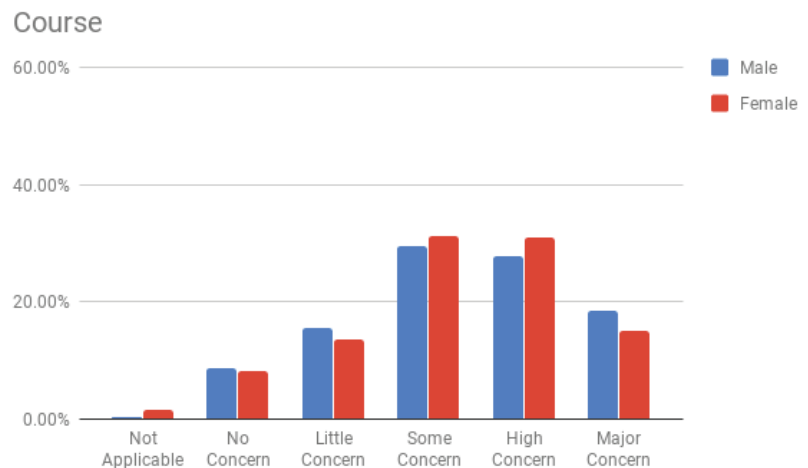

Figure 12: Summary of course concerns by binary gender

4.4.3 Analysis based on institution. Figure 13 presents the summary of responses to the "Choosing the right courses" prompt by institution. Considering all responses grouped by institution, the typical proportion of major or high concern ranges from 19\% to $62 \%$ which places CC1 as the lowest of the Course Concerns when ranked by modal responses, but still in the top half of all concerns (number 11 of 29).

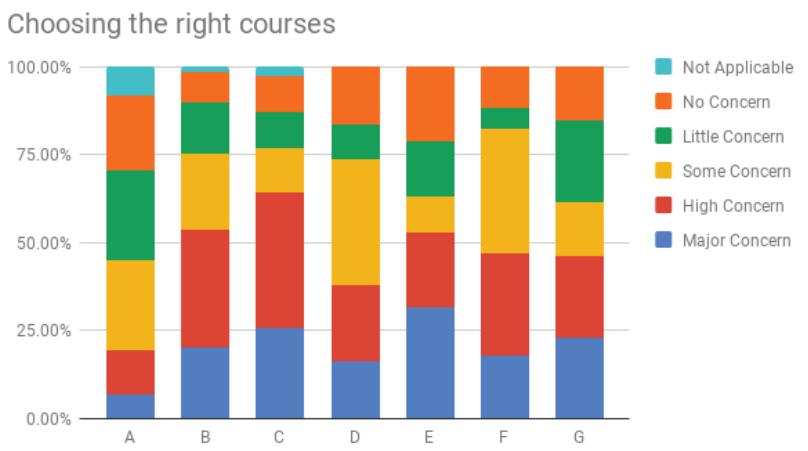

Figure 13: Course Concern 1 (CC1) - Choosing the right courses

Respondents from Institution A, of all gender classifications, respond indicating noticeably lower concern for "choosing the right courses" as compared to responses from other institutions. Approximately $19 \%$ of responses from Institution A (16\% female, $19 \%$ male) indicated major or high concern for this item.

Figure 14 presents the summary of responses to the "Workload expectation" prompt by institution. Considering all responses grouped by institution, the typical proportion of major or high concern is 


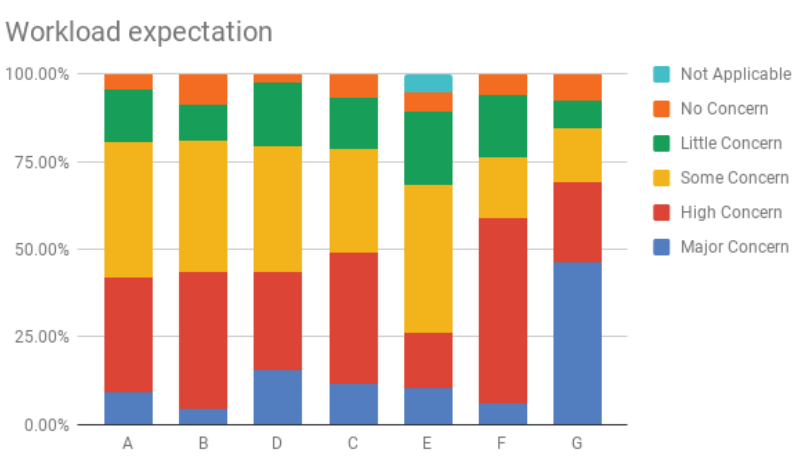

Figure 14: Course Concern 2 (CC2) - Workload expectation

in the range of $42 \%$ to $69 \%$, which places this category fifth of all concerns ranked by modal response.

Respondents from Institution E, of all gender classifications, respond indicating noticeably lower concern for CC2: "Workload expectation" as compared to responses from other institutions.

Female respondents from Institutions B, C and D respond indicating noticeably higher concern for $\mathrm{CC} 2$ as compared to responses from males at the same institutions. At Institution B, 70\% female and 39\% male indicated major or high concern for item CC2. At Institution C, $70 \%$ female and 39\% male indicated major or high concern for item CC2. At Institution D, 53\% female and 44\% male indicated major or high concern for item CC2.

Figure 15 presents the summary of responses to "Managing my time well prompt by institution". Considering all responses by grouped by institution, the typical proportion of major or high concern is in the range of $39 \%$ to $77 \%$, which places this second among all concerns ranked by modal response.

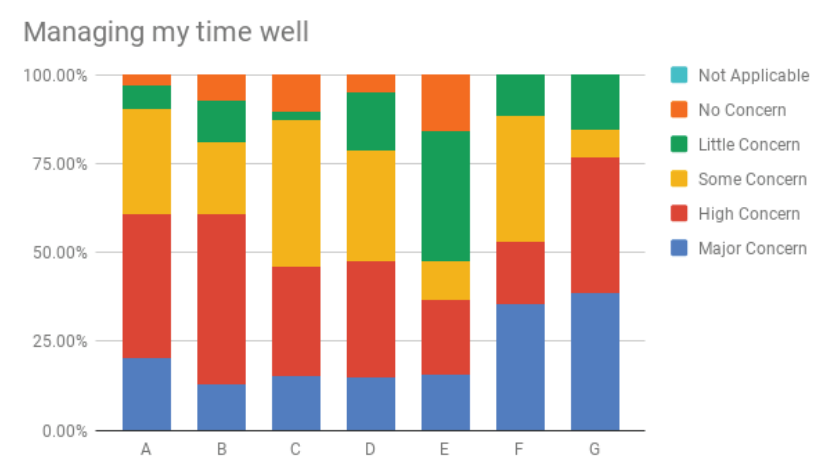

Figure 15: Course Concern 3 (CC3) - Managing my time well

Less than half (39\%) of the respondents from Institution E indicated major or high concern for this item, which is the lowest of responses grouped by institution. When looking at the responses from Institution $\mathrm{E}$ by gender identity, a noticeable difference appears: $29 \%$ female respondents and $45 \%$ of male respondents indicated major or high concern for this item.
Figure 16 presents the summary of responses to the "Liking the course" prompt by institution. Considering all responses by grouped by institution, the typical proportion of major or high concern is in the range of $33 \%$ to $53 \%$, which places CC4 as the second lowest of the Course Concerns when ranked by modal responses, but still in the top half of all concerns (number 9 of 29) among all respondents.

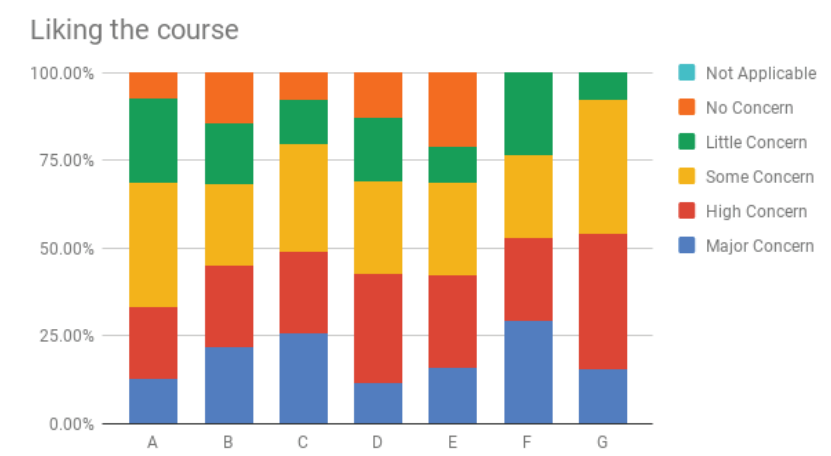

Figure 16: Course Concern 4 (CC4) - Liking the course

Less than half (39\%) of the respondents from Institution A indicated major or high concern for item CC4, the lowest of the responses grouped by institution. When looking at the responses from Institution A by gender identity, a noticeable difference appears: $14 \%$ female respondents and $55 \%$ of male respondents indicated major or high concern for item CC4. A similar, but not as dramatic, pattern is present for Institution $\mathrm{C}$ for which approximately half of the respondents indicated major or high concern for item CC4. When looking at the responses from Institution $\mathrm{C}$ by gender identity, a noticeable difference appears: $29 \%$ female respondents and $52 \%$ of male respondents indicated major or high concern for item CC4. In contrast, for Institution D, $60 \%$ of female respondents indicated major or high concern for item CC4 compared to only $31 \%$ of male respondents.

Figure 17 presents the summary of responses to "Being good at the course" prompt by institution. Considering all responses by grouped by institution, the typical proportion of major or high concern is in the range of $41 \%$ to $69 \%$, which places CC5 as seventh of the 29 concerns among all respondents.

Female respondents from Institutions $\mathrm{B}$ and $\mathrm{C}$ respond indicating noticeably higher concern for $\mathrm{CC} 5$ as compared to responses from males at the same institutions. At Institution B, 80\% female and 53\% male indicated major or high concern for item CC5. At Institution C, $86 \%$ female and $58 \%$ male indicated major or high concern for item CC5.

Figure 18 presents the summary of responses to the "Feeling prepared" prompt by institution. Considering all responses by grouped by institution, the typical proportion of major or high concern is in the range of $37 \%$ to $60 \%$, which places CC6 as 6 th of the 29 concerns among all respondents.

Approximately $36 \%$ of the respondents from Institution E indicated major or high concern for item CC6, the lowest of the responses grouped by institution. When looking at the responses from Institution $\mathrm{E}$ by gender identity, a noticeable difference appears: 


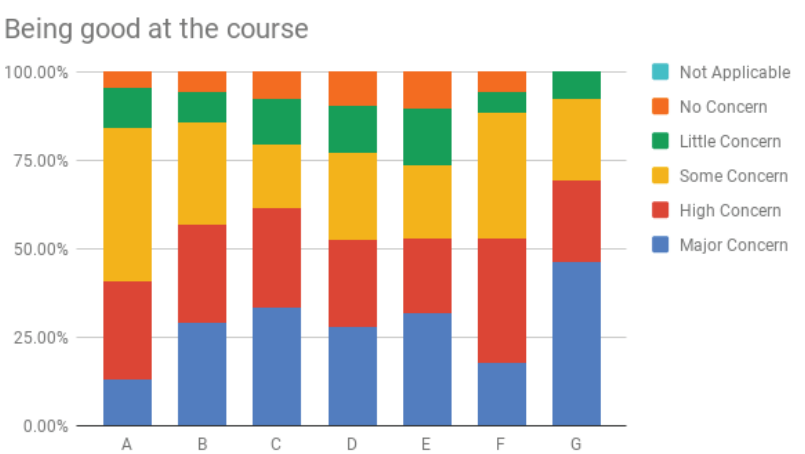

Figure 17: Course Concern 5 (CC5) - Being good at the course

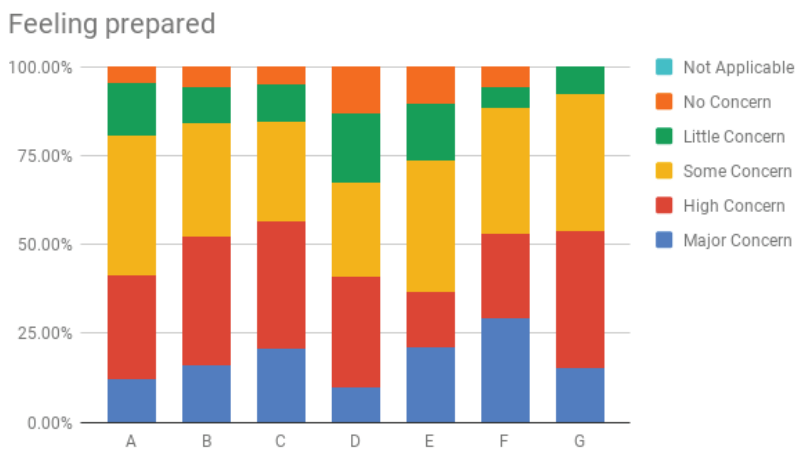

Figure 18: Course Concern 6 (CC6) - Feeling prepared

$25 \%$ female respondents and $48 \%$ of male respondents indicated major or high concern for item CC4. A similar, but not as dramatic, pattern is present for Institution F for which less about half (54\%) of the respondents indicated major or high concern for item CC6. When looking at the responses from Institution $\mathrm{F}$ by gender identity, a noticeable difference appears: $46 \%$ female respondents and $54 \%$ of male respondents indicated major or high concern for item CC6.

This pattern is also present for Institution $C$ for which nearly $55 \%$ of the respondents indicated major or high concern for item CC6. When looking at the responses from Institution $\mathrm{C}$ by gender identity, a noticeable difference appears: $83 \%$ female respondents and $66 \%$ of male respondents indicated major or high concern for item CC6.

Figure 19 presents the summary of responses to the "The possibility of failing, and any repercussions" prompt by institution. Considering all responses by grouped by institution, the typical proportion of major or high concern is in the range of $33 \%$ to $64 \%$, which places $\mathrm{CC} 7$ as first of 29 concerns among all respondents.

Female respondents from Institutions $\mathrm{C}$ and $\mathrm{F}$, respond indicating noticeably higher concern for $\mathrm{CC} 7$ as compared to responses from males at the same institutions. At Institution C, 86\% female and 58\% male indicated major or high concern for item CC7. The difference is even more dramatic at Institution $\mathrm{F}$ for which $67 \%$ female and $22 \%$ male indicated major or high concern for item CC7.

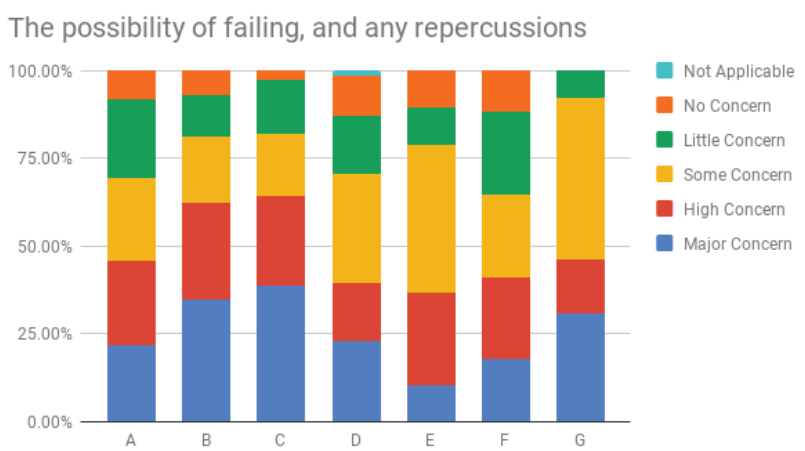

Figure 19: Course Concern 7 (CC7) - The possibility of failing, and any repercussions

\subsection{Lecturer/Professor Concerns}

4.5.1 Introduction. The general concern labeled "Lecturer/Professor" is a collection of three survey items:

- (LPC 1) Level of friendliness

- (LPC 2) Willingness/availability to help

- (LPC 3) Level of interest of the class/topic

$\begin{array}{ll}\text { Lecturer/Professor } & \\ 60.00 \% & \text { Male }\end{array}$

$40.00 \%-$

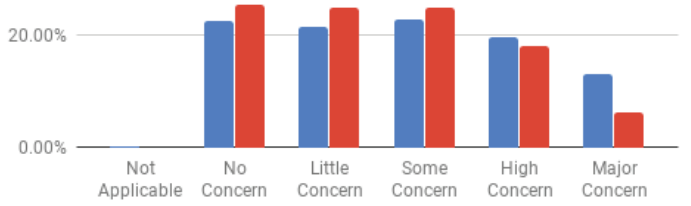

Figure 20: Summary of lecturer/professor concerns by binary gender

4.5.2 Analysis by binary gender. Figure 20 shows no obvious difference between the responses of these two groups. However, when looking into the responses by individual concern, and considering institution, or institution-gender subgroups, a number of differences in responses are found, as will be discussed below.

4.5.3 Analysis based on institution. Figure 21 presents the summary of responses to the "Level of friendliness" prompt by institution. Considering all responses grouped by institution, the typical proportion of major or high concern is in the range of $17 \%$ to $28 \%$ (noting that institution $\mathrm{G}$ is an outlier in this respect, with a total of $46 \%$ ), which places LPC1 in a low position (number 25 of 29) in the list of concerns among all respondents ranked by modal response.

Approximately $19 \%$ of responses from Institution A (16\% female, $19 \%$ male) indicated major or high concern for item LPC1. In this 


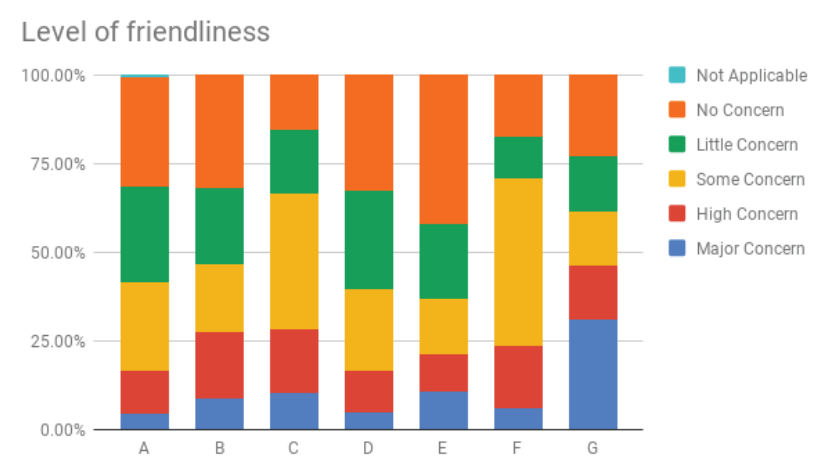

Figure 21: Lecturer/Professor Concern 1 (LPC1) - Level of friendliness

institution, 7\% female and 19\% male indicated major or high concern for item LPC1. The opposite pattern is present in responses by gender in Institutions B and C (in which $27 \%$ and $28 \%$ of the respondents, respectively, indicated major or high concern for item LPC1), where the responses for LPC1 were as follows: Institution B, 40\% female and 25\% male indicated major or high concern; Institution C, $43 \%$ female and $26 \%$ male indicated major or high concern.

Figure 22 presents the summary of responses to the "Willingness/availability to help" prompt by institution. Considering all responses grouped by institution, the typical proportion of major or high concern is in the range of $28 \%$ to $60 \%$, which places LPC2 as number 3 on the list of top concerns among all respondents ranked by modal response. Very few of the respondents from Institution D reported major concerns in this area, likely to be a reflection of the very regular scheduled support sessions which are a key feature of distance education.

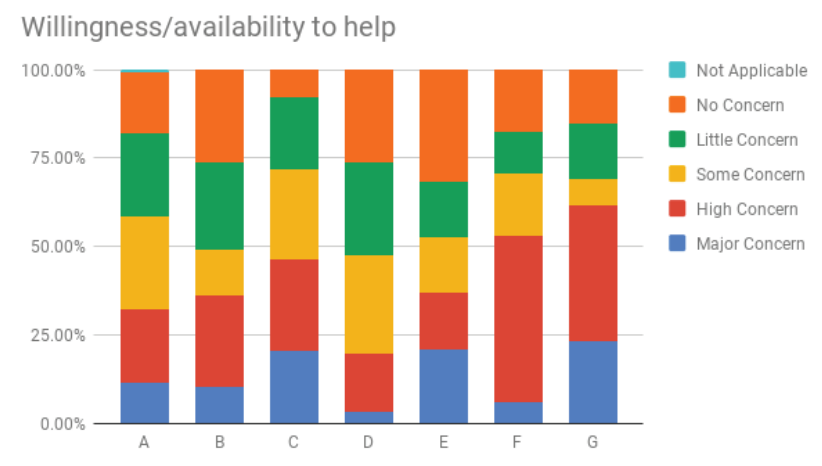

Figure 22: Lecturer/Professor Concern 2 (LPC2) - Willingness/availability to help

Female respondents from Institutions B and C respond indicating noticeably higher concern for LPC2 as compared to responses from males at the same institutions. At Institution B, 70\% female and 39\% male indicated major or high concern for item LPC2. The difference is about the same at Institution C for which $71 \%$ female and $36 \%$ male indicated major or high concern for item LPC2.
Figure 23 presents the summary of responses to the "Level of interest of the class/topic" prompt by institution. Considering all responses grouped by institution, the typical proportion of major or high concern is in the range of $27 \%$ to $41 \%$, which places LPC3 as number 12 on the list of top concerns among all respondents ranked by modal response. Compared to responses from the campus-based institutions, respondents from Institution D show a lower level of concern in this category, most likely again resulting from the high level of scheduled support provided in the distance education situation.

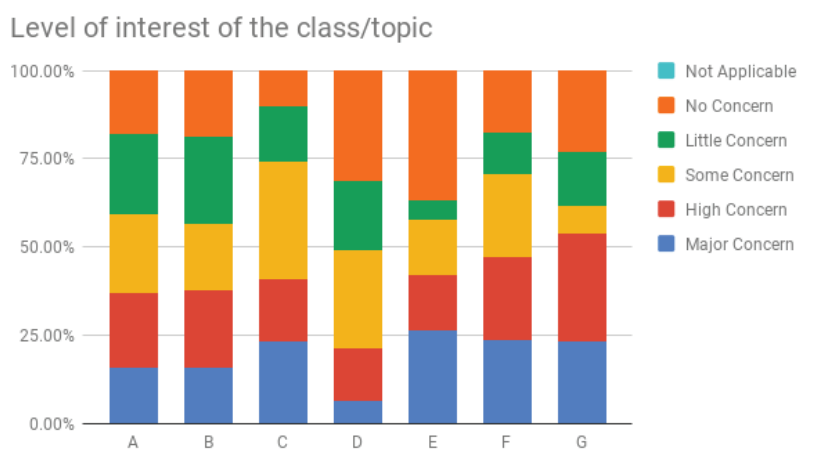

Figure 23: Lecturer/Professor Concern 3 (LPC3) - Level of interest of the class/topic

When looking at the responses by gender identity from Institutions $\mathrm{A}, \mathrm{C}, \mathrm{E}$, and F, a noticeable differences appears. At Institution A, $19 \%$ female as compared to $43 \%$ male indicated major or high concern for item LPC3. At Institution C, 29\% female as compared to $45 \%$ male indicated major or high concern for item LPC3. At Institution E, $14 \%$ female as compared to $54 \%$ male indicated major or high concern for item LPC3. At Institution F, 0\% female as compared to $33 \%$ male indicated major or high concern for item LPC3.

\subsection{Study Experience Concerns}

4.6.1 Introduction. The study experience category consists of three questions dealing with the students' anticipated academic work environment and study experience: "class size (too big/too small)", "city size and location" and "different learning environments; e.g. lecture halls, labs, exercise rooms, ...". This category was created to better understand any concern prospective students may have when considering a transition to an "alien" environment - one that would be widely different from their previous one.

4.6.2 Analysis by binary gender. Figure 24 indicates that $35 \%$ of both male and female respondents have not reported any concern with their study experience. The data itself seems skewed towards less concern, with less than $20 \%$ of participants of either gender reporting high or major concern. Typically, female students seem to report more concern than males on the lower levels of the scale (some concern: $24 \%$ female, $19 \%$ male; little concern: $23 \%$ female, $30 \%$ male).

4.6.3 Analysis based on institution. Figure 25 shows the data split by institution for the question "class size (too big/too small)". 


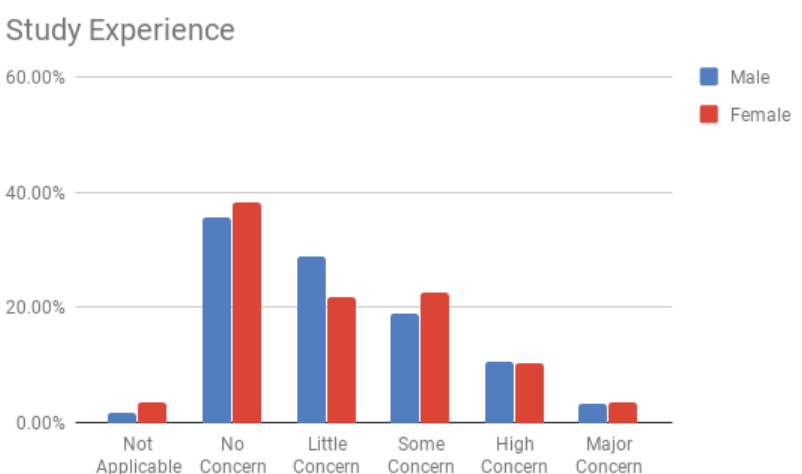

Figure 24: Summary of study experience concerns by binary gender

There are relatively low reports of high and major concern $(<15 \%)$ reported for most institutions, with the outliers being institutions $\mathrm{C}$ and $\mathrm{G}$. For the former, this is due to to students being moved to new facilities with smaller rooms. For the latter, this is attributed to a change in scenery and environment. There were no Institution $\mathrm{D}, \mathrm{E}$ or F responses of major concern. Institution D also had low responses for high concern, which is likely due to the organization of students into tutor groups of maximum size (typically) 20 .

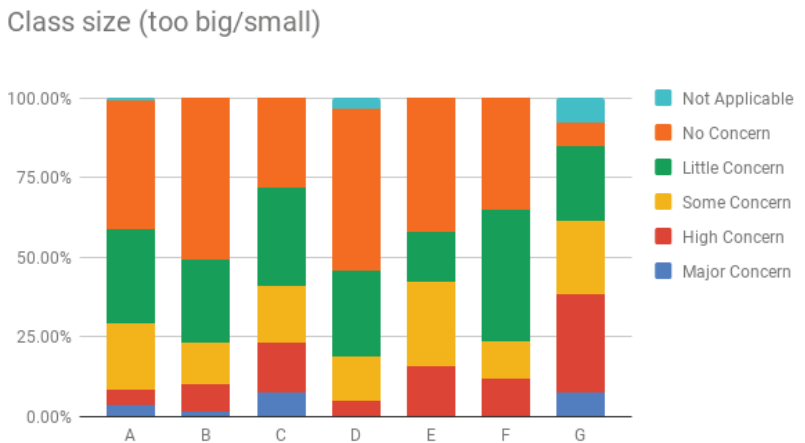

Figure 25: Study Experience Concern 1 (SEC1) - Class size (too big/too small)

Figure 26 shows the data split by institution for the question "city size and location". Concern is quite low, with less than $25 \%$ of respondents from each institution reporting high and major concern. This is surprising as many students coming into the institutions surveyed are sometimes doing so from rural and remote areas; the researchers expected that moving to a big city would cause concern, and that that would be displayed here. As it stands, clearly this issue is of low concern for students, particularly but unsurprisingly those from Institution D who study online.

Figure 27 shows the data split by institution for the question "different learning environments; e.g. lecture halls, labs, exercise rooms, ...". It can be seen that concern varies by institution, with no high or major concern reported by Institution F, and with the

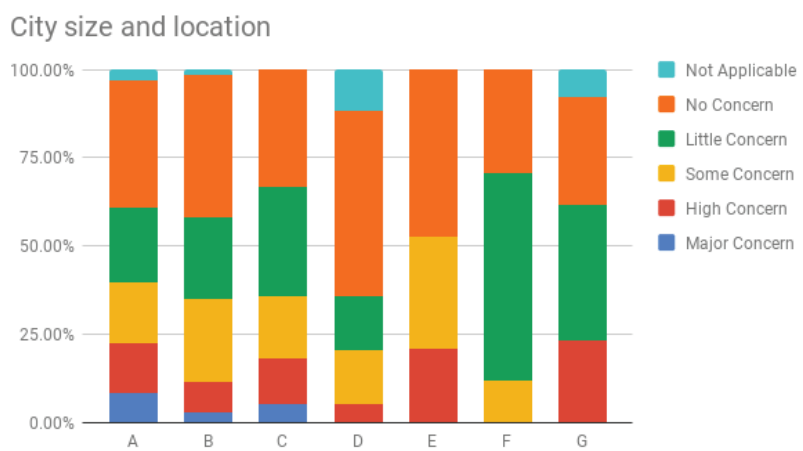

Figure 26: Study Experience Concern 2 (SEC2) - City size and location

highest report of concern coming from Institution G (high concern: $31 \%$; major concern: $23 \%$ ). The concerns reported by students from Institution $\mathrm{G}$ are attributed to the fact that the Faculty at this institution teaches a number of degrees, including Computer Science, Nursing and Biomedical Engineering - thus it is posited that learning environments may be multi-purpose rather than being custom-built for teaching CS.

\section{Different learning environments (e.g. lecture halls, exercise} rooms, labs, ..)

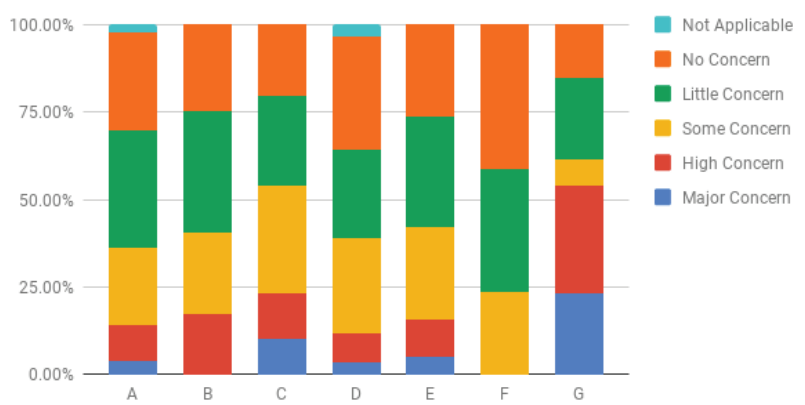

Figure 27: Study Experience Concern 3 (SEC3) - Different learning environments

\subsection{Accessibility Concerns}

4.7.1 Introduction. This category consisted of one question, allowing students to express potential concern with accessibility, disability services and student support at their institution. The questions were prefaced with the following preamble: "Accessibility issues include requesting support (e.g. "will I get support with my dyslexia?"), or concerns about navigating the environment (e.g. "can I get my wheelchair to class?"). If you do not have any accessibility issues, please tick the "Not Applicable box".

4.7.2 Analysis by binary gender. Figure 28 shows the results of the Accessibility concern split by gender. It is interesting to note high results across genders for the "Not Applicable" and "No 


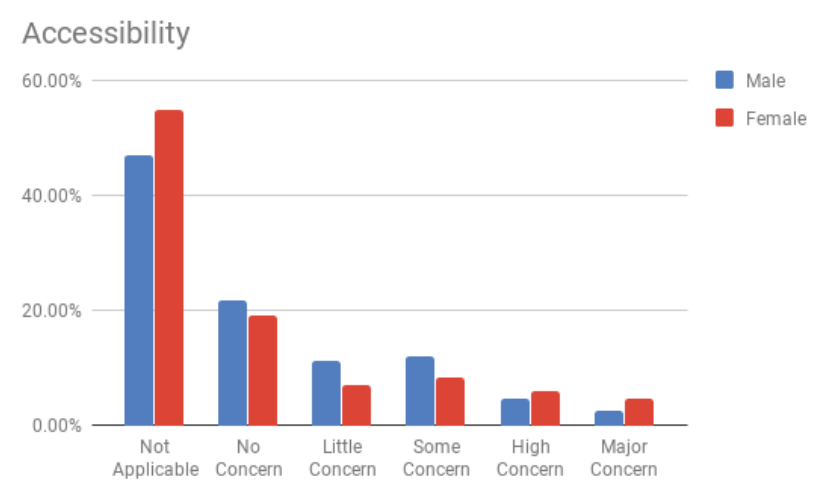

Figure 28: Summary of accessibility concerns by binary gender

Concern" granularities, as not all respondents would have required accessibility support in their institutions. Whilst some data points indicate higher concern reported from the female population, the authors posit that these numbers in particular are very subjective to a student's own needs; that is to say, the increase in concern for the female population may simply indicate that during this data collection process, more females required accessibility support than males.

The authors posit that whilst these numbers indicate an overall low concern, student who did not need additional support may have chosen a lower level of concern, rather than ticking "Not Applicable".

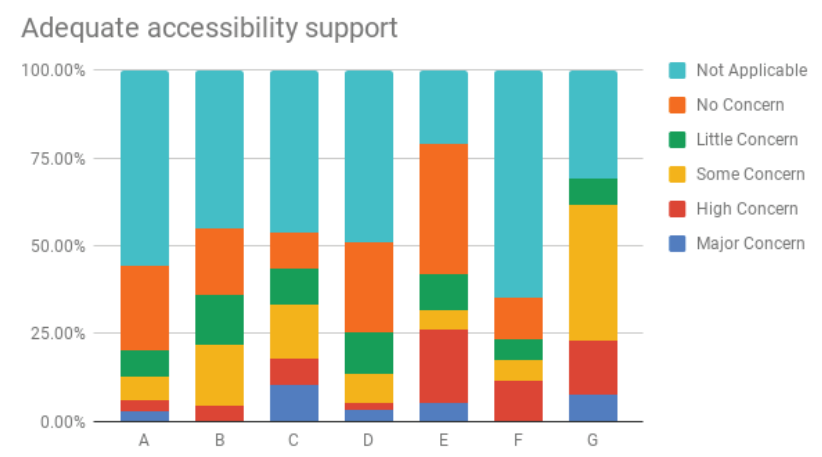

Figure 29: Accessibility Concern 1 (AC1) - Adequate accessibility support

4.7.3 Analysis based on institution. Figure 29 shows the split of the Accessibility data by institution, for the question "adequate accessibility support". It is interesting to note no major concerns for Institutions B and F, and low major concerns $(<10 \%)$ across the other institutions.

Overall, all Institutions (bar G) have reported low levels of concern - however, over $50 \%$ of respondents from Institution $G$ have indicated some level of concern or higher. Further investigation identified that there was no mention of accessibility on the website for Institution $\mathrm{G}$ - which could indicate that students who required this support may not have known where or how to access it.

\subsection{Social Concerns}

4.8.1 Introduction. This category consisted of three questions, allowing students to identify potential concerns with their social situation. Attending higher education is, for most, the first experience of leaving the home nest and becoming more independent; part of that transition is to experience a change in the student's existing peer group and integrating with new groups, which for some may cause anxiety. The questions allowed students to express concern for "ability to make friends", "peer pressure" and "feeling like an outsider".

4.8.2 Analysis by binary gender. When splitting the data by gender (Figure 30), there is no clear difference for any of the concern choices. $31 \%$ of males and $32 \%$ of females indicated that they had no social concerns. Male students indicated slightly higher levels of concern than the female students, but the difference between the two groups is too small to be significant. In itself this is interesting, as one can conclude that social anxiety is not any more concerning for either gender.

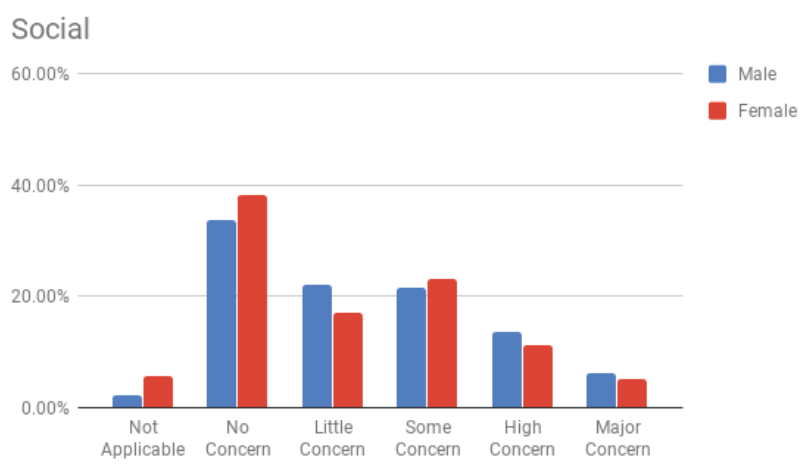

Figure 30: Summary of social concerns by binary gender

4.8.3 Analysis based on institution. Figure 31 shows the data split by institution for the question "ability to make friends". Whilst at first glance the data looks fairly similar across the board, it is interesting to note that over $23 \%$ of students from each campusbased institution reported high or major concern levels with making friends. The numbers are higher for Institutions E and F - these institutions are in the two largest countries included in the survey, so it could be posited that students in these countries have to move further afield from home, and from established friend groups (especially when compared to Institution B, where most students are a few hours away from home). The data from Institution D shows that over $50 \%$ of students have exhibited some level of concern about making friends, which is interesting given that this institution is the only distance-learning one in the survey. Discussions with representatives from that institution highlighted the point that distance learners can feel isolated from each other and from a 
community of practice beyond the computer screen. These students may seldom or never actually meet and socially interact with other students. For this subset of participants, the word "friends" may well mean "make peer relationships", or "establish a community of practice".

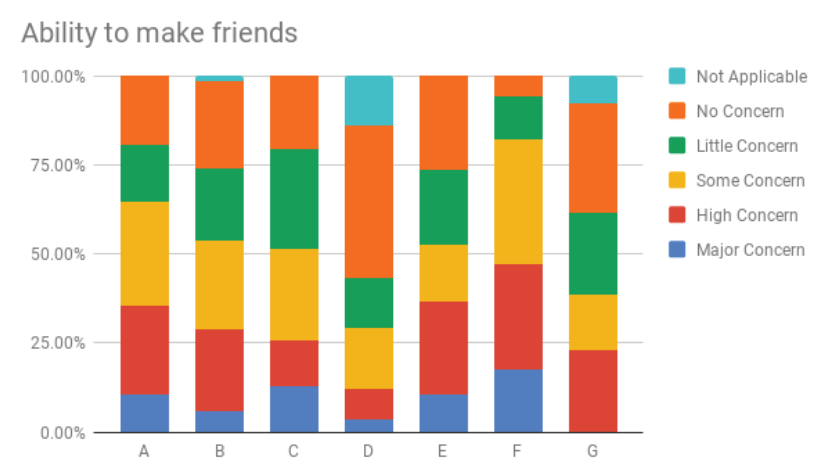

Figure 31: Social Concern 1 (SC1) - Ability to make friends

Figure 32 shows the data split by institution for the question "peer pressure". There are mostly low levels of concern across all participants.

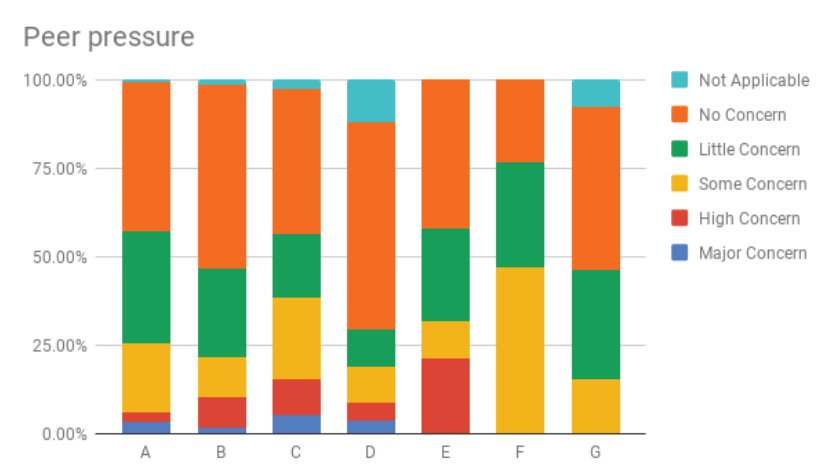

Figure 32: Social Concern 2 (SC2) - Peer pressure

Figure 33 shows the data split by institution for the question "feeling like an outsider". The level of concern reported in this instance was quite low - although $47 \%$ of Institution F students indicated some concern. This can be attributed to the fact that this institution is located in a state which has a large amount of disperse school districts. Therefore, for many of the students at Institution $\mathrm{F}$, starting university is their first time in a large city and this often leads to them experiencing culture-shock borne out of isolation.

\subsection{Homesickness Concerns}

4.9.1 Introduction. This category consisted of four questions, allowing students to express potential concerns with the items "missing my friends/family/pets", "distance from home", "ability to go home", and "frequency of going home". As Institution D students

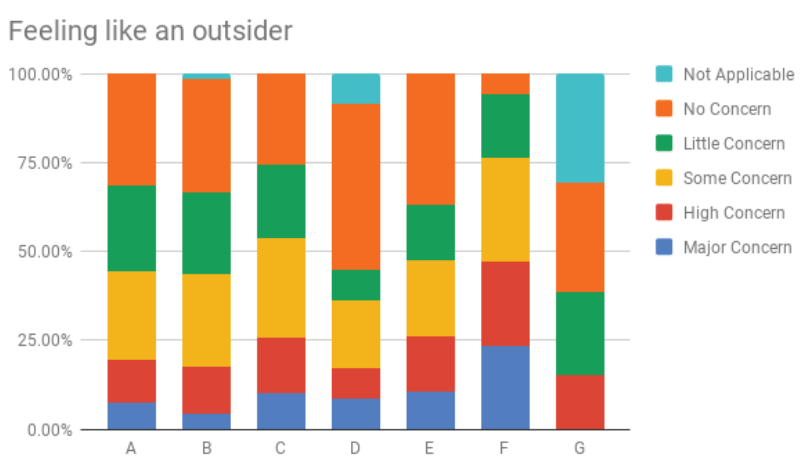

Figure 33: Social Concern 3 (SC3) - Feeling like an outsider

are primarily online distance learners, they were not asked any of the homesickness questions.

4.9.2 Analysis by binary gender. Figure 34 shows the results of the Homesickness concern split by gender. The level of concern expressed by female respondents appears to be greater than that of the male respondents for all options indicating some or more concern, whilst the male respondents indicated a far larger proportion indicating "No Concern".

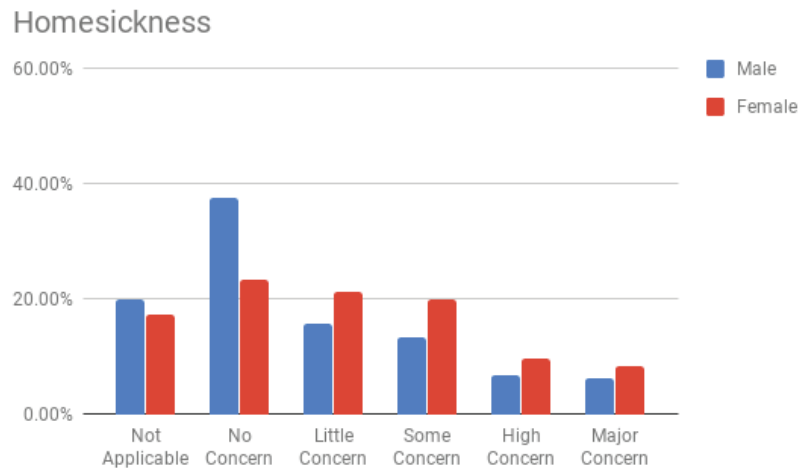

Figure 34: Summary of homesickness concerns by binary gender

4.9.3 Analysis based by institution. Figure 35 shows the data split by institution for question "missing my friends/family/pets". Students from institution E expressed the highest level of major concern at $26 \%$. Institutions $\mathrm{F}$ and $\mathrm{G}$ have similar high concern levels. Students from Institution A responded with the lowest numbers of high and major concerns.

Students in Ghana are typically used to being independent, as most high schools have boarding facilities. Thus, the data from Institution $G$ is surprising - but could be attributed to a number of international students who have difficulty adjusting in the new environment away from home. Institution A results could be explained by the fact that Swedish students are known for being more independent and individualistic - a normal characteristic for 
the Nordic population - as opposed to more close-knit families elsewhere in the continent.

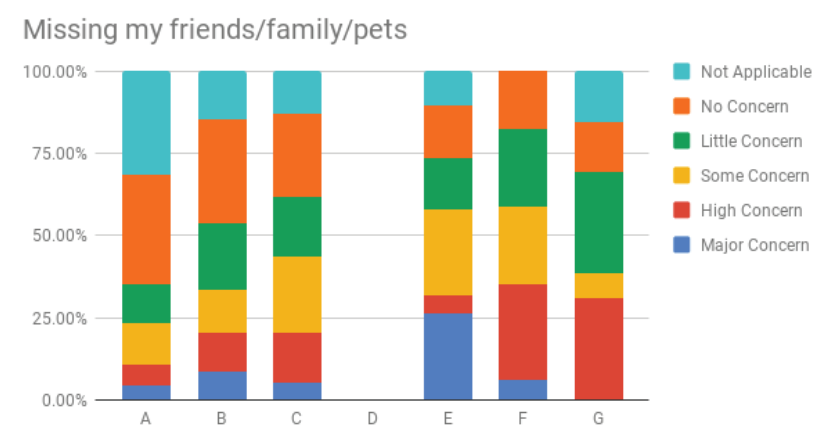

Figure 35: Homesickness Concern 1 (HSC1) - Missing my friends/family/pets

Figure 36 shows the data split by institution for question "distance from home". The comments made for the Ghanian institution in HSC1 above are applicable to this subcategory. The low concern reported by Institution A is correlated with the fact that in Sweden there are a number of frequent and reliable public transportation options from the capital, making traveling back home unproblematic.

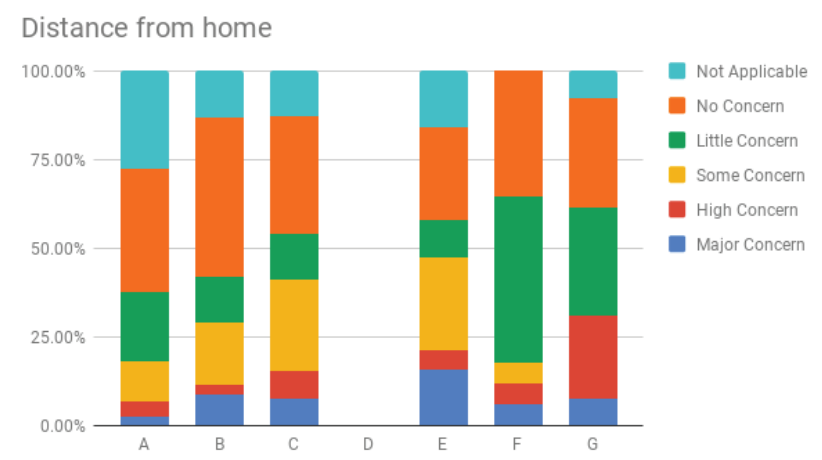

Figure 36: Homesickness Concern 2 (HSC2) - Distance from home

Figure 37 shows the data split by institution for question "ability to go home". Institution A shows the lowest level of concern: it is not difficult for these students to go home as the public transportation network for the country is well connected. In contrast, institution $\mathrm{C}$ has the highest levels of concern, with over $25 \%$ of respondents expressing high or major concern.

Figure 38 shows the data split by institution for question "frequency of going home". Institution G reported a high concern of $15 \%$, in part due to the large international cohort that is typically admitted into their undergraduate programme.

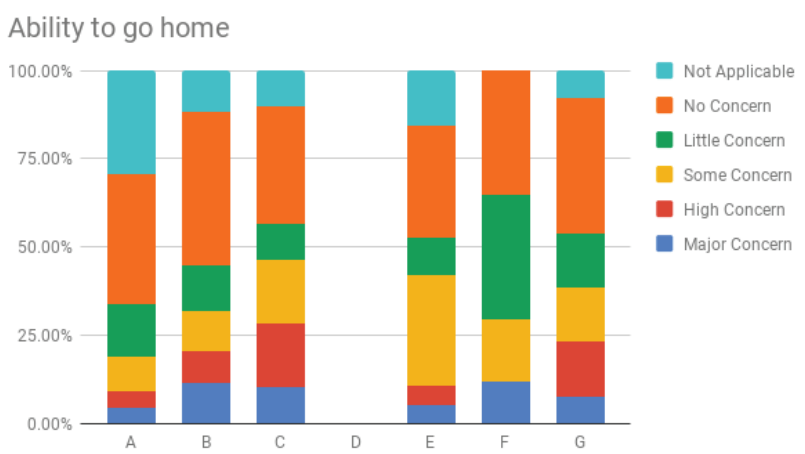

Figure 37: Homesickness Concern 3 (HSC3) - Ability to go home

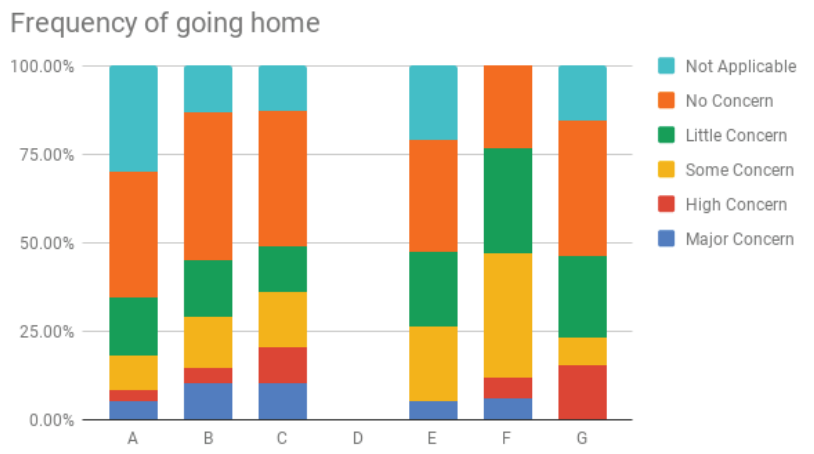

Figure 38: Homesickness Concern 4 (HSC4) - Frequency of going home

\section{DISCUSSION}

Analysing the data by concern category has allowed comparisons to be made across institutions and according to binary gender. In this discussion section, a comparison of the concern categories is made across the entire sample and according to gender. Findings from the study are then related to Tinto's (2017) conceptual model of student institutional persistence as seen through the eyes of students.

\subsection{Ranking of Concerns}

As the data was collected on an ordinal scale, it was possible to calculate the mode for each question in order to produce rankings. (Mode represents the total number of persons sharing the modal response for each question. modal response is the predominant/most often chosen category). This data is presented in Table 3.

The table clearly shows an overall major concern regarding failing, and high concerns across other course concerns such as workload expectation, time management, feeling prepared and being good at the course. Also of concern is the availability of academic staff, and prospects of securing good employment.

It is interesting - and perhaps worrying - to see these concerns so high up the list. Traditionally, higher education institutions 
Table 3: Concerns Ranked by Mode

\begin{tabular}{|c|c|c|c|}
\hline Rank & Concern & mode & modal response \\
\hline 1 & CC7 - Course Concerns [The possibility of failing, and any repercussions] & 91 & Major Concern \\
\hline 2 & CC3 - Course Concerns [Workload expectation] & 131 & High Concern \\
\hline 3 & LPC2 - Lecturer/Professor Concerns [Willingness/availability to help] & 82 & High Concern \\
\hline 4 & JC2 - Job-related Concerns [Securing good employment after graduation] & 81 & High Concern \\
\hline 5 & CC2 - Course Concerns [Managing my time well] & 122 & Some Concern \\
\hline 6 & CC6 - Course Concerns [Feeling prepared] & 119 & Some Concern \\
\hline 7 & CC5 - Course Concerns [Being good at the course] & 113 & Some Concern \\
\hline 8 & MC1 - Money Concerns [General money concerns] & 109 & Some Concern \\
\hline 9 & CC4 - Course Concerns [Liking the course] & 105 & Some Concern \\
\hline 10 & SC1 - Social Concerns [Ability to make friends] & 87 & Some Concern \\
\hline 11 & $\mathrm{CC} 1$ - Course Concerns [Choosing the right courses] & 86 & Some Concern \\
\hline 12 & LPC3 - Lecturer/Professor Concerns [Level of interest of the class/topic] & 81 & Some Concern \\
\hline 13 & MC2 - Money Concerns [Housing costs ] & 78 & Some Concern \\
\hline 14 & JC1 - Job-related Concerns [Finding/keeping a part-time job] & 77 & Some Concern \\
\hline 15 & SEC3 - Study Experience Concerns [Different learning environments (e.g. lecture halls, ex. rooms, labs, ...)] & 109 & Little Concern \\
\hline 16 & SC2 - Social Concerns [Peer pressure] & 160 & No Concern \\
\hline 17 & SEC1 - Study Experience Concerns [City size and location] & 145 & No Concern \\
\hline 18 & SEC2 - Study Experience Concerns [Class size (too big/small)] & 138 & No Concern \\
\hline 19 & MC3 - Money Concerns [Tuition fees/course fees] & 115 & No Concern \\
\hline 20 & MC4 - Money Concerns [Applying for scholarships/funding] & 113 & No Concern \\
\hline 21 & SC3 - Social Concerns [Feeling like an outsider] & 113 & No Concern \\
\hline 22 & HSC3 - Homesickness Concerns [Ability to go home] & 109 & No Concern \\
\hline 23 & HSC4 - Homesickness Concerns [Frequency of going home] & 106 & No Concern \\
\hline 24 & HSC2 - Homesickness Concerns [Distance from home] & 105 & No Concern \\
\hline 25 & LPC1 - Lecturer/Professor Concerns [Level of friendliness] & 103 & No Concern \\
\hline 26 & HSC1 - Homesickness Concerns [Missing my friends/family/pets] & 84 & No Concern \\
\hline 27 & AC1 - Accessibility Concerns [Adequate accessibility support] & 171 & Not Applicable \\
\hline 28 & HC2 - Housing Concerns [Having to live with flatmates/roommates] & 84 & Not Applicable \\
\hline 29 & HC1 - Housing Concerns [Finding/quality of housing (including items such as meal plans, etc.)] & 63 & Not Applicable \\
\hline
\end{tabular}

make efforts to target concerns such as applying for scholarships, homesickness and finding flatmates - but these are all items that appear at the bottom half of the rankings.

\subsection{Ranking of Concerns by Binary Gender}

The modal data was also analysed by binary gender to identify any issues that were specific to a particular gender group. Perhaps surprisingly, the modal data is very similar for male and female respondents: in 13 of the 29 categories of concern, the modal response category is identical for male and female respondents. Table 4 shows the eight concerns where the differing modal response according to gender featured either a "Major" or a "High" concern. These eight concerns are presented in category order. Again, course concerns are prominent. In addition, money concerns appear to be more important to the male students than the female students. However, further analysis of all the categories of concern identified only two that were significant at $\mathrm{p}<0.05$ : male respondents were more concerned than female respondents about LPC2 - Lecturer/Professor Concerns [Willingness/availability to help]: $\mathrm{U}=9142.5, \mathrm{p}=0.032$. Female respondents were more concerned about HSC2 - Homesickness Concerns [Distance from home]: $\mathrm{U}=5322$, $\mathrm{p}=0.027$.
Considering gender, it is important to note that the similarities in concern greatly exceed the differences. Of the two categories where the gender responses differ significantly, one is evidently an area requiring further attention and investigation (LPC2 - Lecturer/Professor Concerns [Willingness/availability to help]), since it is ranked third of all the modal responses. Further analysis of the qualitative responses will be necessary to better understand the reasons for male respondents having more concerns than female respondents. Regarding the other concern (HSC2 - Homesickness Concerns [Distance from home]), an initial review of the qualitative data confirms the finding. In response to the free text question âĂIJFrom home/school, I thought I would miss...âĂİ, $40 \%$ of the female respondents mentioned family, friends and/or parent(s) compared to only $25 \%$ of the male respondents. Although it appears relatively less urgent than the category LPC2 - Lecturer/Professor Concerns [Willingness/availability to help], given that it is ranked 24 out of 29 of all the concerns overall, nonetheless it may contribute to aspects of student motivation and thus also deserves to be explored further. 
Table 4: Ranking of Concerns by Binary Gender

\begin{tabular}{lll} 
Concern & modal response (male) & modal response (female) \\
\hline MC2 - Money Concerns [Housing costs] & High Concern & Some Concern \\
CC1 - Course Concerns [Choosing the right courses] & Some Concern & High Concern \\
CC2 - Course Concerns [Managing my time well] & Some Concern & High Concern \\
CC3 - Course Concerns [Workload expectation] & High Concern & Some Concern \\
CC6 - Course Concerns [Feeling prepared] & Some Concern & High Concern \\
CC7 - Course Concerns [The possibility of failing, and any repercussions] & Major Concern & High Concern \\
LPC2 - Lecturer/Professor Concerns [Willingness/availability to help] & Little Concern & High Concern \\
LPC3 - Lecturer/Professor Concerns [Level of interest of the class/topic] & High Concern & Some Concern \\
\hline
\end{tabular}

\subsection{Theoretical considerations}

Tinto's [45] conceptual model of student institutional persistence, as seen through the eyes of students, presents student motivation as the outcome of their goals, self-efficacy, sense of belonging and perceived worth or relevance of the curriculum. Whilst goals may relate to completion of their course, whether at the institution that they first enrolled upon or not, Tinto [45] notes that some students may have more limited goals that do not require completion. Motivations may be intrinsic, such as learning and autonomy, or extrinsic, such as income. Motivation in turn contributes to persistence: when faced with challenges, a student's persistence may be less likely without motivation. Tinto [45], stating that "self-efficacy is the foundation upon which student persistence is built". This view reinforces the importance of this study's findings that students are principally focused upon course concerns. If, at the outset of their higher education, students have concerns over success in their course, this may have a negative impact on their self-efficacy, which in turn may lead them to become discouraged and reduce their belief in their ability to succeed.

In Tinto's model [45], the absence of a sense of belonging - such as to a community of faculty, staff and other students - can reduce motivation to persist. Whilst Homesickness did not feature highly in the overall ranking of concerns, the evidence of this study is that at least one aspect (distance from home) is felt more acutely by female students than by male students. It may be that some female students would benefit from actions to draw them into the community by means of regular opportunities to interact in shared experiences. Tinto [45] notes that a sense of belonging may relate to academic belonging, but it also can relate to diversity. Gender balance recruitment challenges may also be a factor, therefore, that leads to greater concern about homesickness by female students than by male students.

Perceptions of curriculum, as described in Tinto's conceptual model [45] of student institutional persistence, feature quality of the curriculum and the relevance of the curriculum to the students. Faculty teaching methods may be relevant to these perceptions. In this study, there may be two directly related concerns. Firstly, LSC2 - Lecturer/Professor Concerns [Willingness/availability to help] may be a proxy for curricular quality or relevance: if faculty appear to be indifferent to the teaching needs of students, students may judge that the curriculum is relatively unimportant to them. Secondly, JC2 - Job-related Concerns [Security good employment after graduation] may be related to perceptions of curriculum. If students have such employment-related concerns at the outset of their higher education, it may indicate an amount of doubt about the value to them of commitment and effort to their study.

This study has identified four concerns in particular which students deemed to be of major or high concern: course related (the possibility of failing and workload expectation), lecturer/professor related (willingness/availability to help) and job-related (securing good employment after graduation). Female students also had homesickness concerns. Each of these categories can be judged to correspond to Tinto's [45] conceptual model of student institutional persistence as seen through the eyes of students: respectively selfefficacy, perceptions of the curriculum, and sense of belonging. The first two of these three also correspond to recent findings by Webb and Cotton [48], that student perceptions of low one-to-one contact with staff and low peer interaction were associated with contemplation of withdrawal. Recommendations relating to these areas will be considered in Section 6 .

\subsection{Threats to Validity}

A number of threats to validity must be considered, as these may impact upon the results and discussion so far.

- Due to circumstances beyond the group's control, the survey was issued at different points across the institutions - some students were still in class, some were in the middle of exams and assessments, and some had finished the class a few weeks prior to the survey being issued. This, as well as external circumstances surrounding exam and assessment time, may have influenced the students' concern and perhaps biased the results towards course concerns. This is mitigated by the fact that previous studies on transition $[42,49]$ have reported that course concerns are always highly ranked by students.

- Running surveys always presents the risk of self-selecting participants. There is perhaps a bigger risk of this occurring for the institutions where participants were invited by email, as it could be posited that only students interested in the subject matter would fill in the survey.

- There was no collection of demographic data, yet being able to split the data by age range or household income may uncover further correlations and trends in the data. This will be considered for future iterations of this work.

- The survey was issued to first year students at the end of the academic year across most of the institutions, so may not be representative of the actual student transition into higher education. This is mitigated, however, by the fact 
that an analysis of the qualitative data clearly indicates that there is overlap - and the issues discussed are aligned with previously reported data [49]. This analysis is being prepared for a future publication.

- The response rate for some institutions was poorer than expected due to the timing of this survey. Institutions that had a response rate lower than 1 in 50 were excluded from the analysis as discussed in Section 3.

\section{RECOMMENDATIONS}

Following the analysis of the self-reported concerns by students and the related discussion, it is possible to make a number of recommendations. It is hoped that these recommendations can be used to develop an understanding of how to best support students' concerns as they transition into higher education; first by institution, then for the students themselves.

\subsection{Recommendations to Institutions}

Based on the findings presented in this work, the following recommendations are suggested at the institutional level:

- Efforts should be made to support students with regard to their course concerns. The possibility of failing is a high or major concern irrespective of gender, and students need to know what remedial options are available in advance of any potential failure to understand that it is not terminal to their degree at such an early stage. Institutions should be aware of the importance of self-efficacy and what capacity they have to support students in need. Tinto (2017) draws upon published good practice to provide a summary of potential responses that institutions should consider.

- The level of concern differed for some categories between male and female respondents. This should be factored into plans to address concerns, to ensure that no under-represented group feels that efforts are concentrated at mitigating the concerns of other groups. Recognising the importance of a "sense of belonging", Tinto (2017) advocates institutions addressing this at the very start of the student's higher education experience, giving suggestions pertinent to each of the academic and the social sphere.

- Regular reviews of the quality of the curriculum are the norm in higher education. Work noted earlier of e.g. Barker [5], work reported by Ladner and Vandegrift (2011), corresponds to what Tinto calls the relevance of the curriculum to the students. Evidence from the current study suggests a need for regular evaluation of what students perceive to be the value and relevance of what they are being asked to learn.

- Run an evaluation such as the survey presented in this work annually as a longitudinal instrument. This should allow you to measure the levels of concern that are particular to your own institutional and national context, thereby to better understand the concerns that your transitioning students are facing.

\subsection{Recommendations to Transitioning Students}

Switching focus to individual students who are transitioning, the following recommendations are suggested based on the findings of this work:

- There may be a lot of concerns about your chosen course, however this is the beginning of an academic journey and there is always flexibility in the system. Whilst this flexibility may not be immediately apparent, effort spent investigating it will pay off. Whether you fear failure or the burdens of the work, reach out to your academic community (peers, teachers, advisors) and discover what options are available to either change, remedy or simply confirm your current direction.

- You may experience a range of practical concerns regarding money, housing and your future career. These concerns are partly due to independent living and these must be managed alongside the educational component of university life. All students will face these challenges in different ways, however the transition from your former life to university life, the management of course and practical concerns is an interlinked part of this development.

- Appreciate that your peers will share some of your concerns, yet others will have completely different concerns from your own. This is important to understand that you are not isolated in your own concerns, and that others may feel isolated with their concerns. The academic community thrives upon diversity and empathy for others. Embrace the differences and support each other in mitigating concerns as an ongoing and continuous aspect of your studies.

\section{CONCLUSION}

This working group was convened to consider student concerns with regards to their transition into higher education, based on work previously carried out by $[42,49]$. Data was collected and analysed from seven institutions across five countries, with the analysis focussing primarily on the gender split and on any institutional differences.

A number of conclusions can be made. There is little difference in concern when considering the data on a binary gender level, showing that male and female students share the same level of concern across a variety of categories. Ranking the concerns by question shows that the highest concerns experienced by students are related to their course, with failing and the repercussions of doing so being the highest rated concern.

This analysis has been used to make a number of recommendations to institutions and to students on how to best manage their concerns.

\subsection{Future Work}

There are a number of avenues which can be taken forward from this work.

First, more institutions should be recruited for a similar study to run in the next academic year, with enough time given to each institution to maximise the data collection. This gathered data would allow for a longitudinal comparison between years, to get a 
more detailed view of the data and better understand any specific issues that are trending.

Second, an amount of qualitative data was not fully explored in this paper. There is a need to further analyse that qualitative data to interpret more completely the student responses and get a better understanding of their concerns. Targeted statistical analysis can also be extended across the data to uncover any further significant differences between the groups, allowing for additional recommendations.

Finally, an amount of data was gathered regarding the concerns of individuals who identified their gender as non-binary. Whilst that data was excluded from this paper due to the small sample, it merits further discussion in a future publication.

\section{ACKNOWLEDGEMENTS}

The authors would like to thank Angela Siegel and Joseph AbandohSam for their efforts in collecting some of the data used in this survey, as well as all the students who took the time to share their concerns with us.

\section{REFERENCES}

[1] Everaldo Aguiar, Nitesh V Chawla, Jay Brockman, G Alex Ambrose, and Victoria Goodrich. 2014. Engagement vs performance: using electronic portfolios to predict first semester engineering student retention. In Proceedings of the Fourth International Conference on Learning Analytics And Knowledge. ACM, 103-112.

[2] Ghassan Alkadi, Theresa Beaubouef, Eric Patton, and Savannah Brown. 2011. Virtualization of our University for the Recruitment and Orientation of new Students. Fournal of Computing Sciences in Colleges 26, 4 (2011), 71-77.

[3] Ruba Alkhasawneh and Rosalyn S Hobson. 2012. Identifying significant features that impact URM students academic success and retention upmost using qualitative methodologies: focus groups. In American Society for Engineering Education. American Society for Engineering Education.

[4] Sattar Ameri, Mahtab J Fard, Ratna B Chinnam, and Chandan K Reddy. 2016. Survival analysis based framework for early prediction of student dropouts. In Proceedings of the 25th ACM International on Conference on Information and Knowledge Management. ACM, 903-912.

[5] Lecia J Barker, Charlie McDowell, and Kimberly Kalahar. 2009. Exploring factors that influence computer science introductory course students to persist in the major. In ACM SIGCSE Bulletin, Vol. 41. ACM, 153-157.

[6] Theresa Beaubouef and Patrick McDowell. 2008. Computer science: student myths and misconceptions. Journal of Computing Sciences in Colleges 23, 6 (2008), 43-48.

[7] Isaac Biney. 2015. Exploring Graduate Unemployment Problem in Ghana: Challenges and Strategies. ISSN 2347-8225 (02 2015), 1-18.

[8] Jennifer M. Blaney. 2018. Looking Beyond Representation: How Women Develop Their Leadership Perceptions During the Introductory Computing Course. In Proceedings of the 49th ACM Technical Symposium on Computer Science Education (SIGCSE '18). ACM, New York, NY, USA, 453-458. https://doi.org/10.1145/ 3159450.3159458

[9] Angela Bowles, Ron Fisher, Ruth McPhail, Daniela Rosenstreich, and Alexandra Dobson. 2014. Staying the distance: students' perceptions of enablers of transition to higher education. Higher Education Research \& Development 33, 2 (2014), 212225.

[10] Phinehas Nathaniel Bynum. 2014. Digital Orientation for New Students: Hiding the Tech Behind the Fun.... In Proceedings of the 42Nd Annual ACM SIGUCCS Conference on User Services (SIGUCCS '14). ACM, New York, NY, USA, 37-38. https://doi.org/10.1145/2661172.2661187

[11] Yujing Chen, Aditya Johri, and Huzefa Rangwala. 2018. Running out of stem: a comparative study across stem majors of college students at-risk of dropping out early. In Proceedings of the 8th International Conference on Learning Analytics and Knowledge. ACM, 270-279.

[12] Anthony Cook and Janet Leckey. 1999. Do expectations meet reality? A survey of changes in first-year student opinion. Fournal of Further and Higher Education 23, 2 (1999), 157-171.

[13] Teresa Dahlberg, Tiffany Barnes, Kim Buch, and Audrey Rorrer. 2011. The STARS alliance: Viable strategies for broadening participation in computing. ACM Transactions on Computing Education (TOCE) 11, 3 (2011), 18.

[14] Jill Denner, Louise Ann Lyon, and Linda Werner. 2015. Does Gender Matter? Women Talk about Being Female in College Computing Classes. In Proceedings of the Third Conference on GenderIT. ACM, 44-48.
[15] D Dickerson, F Solis, V Booth Womack, T Zephirin, and CS Stwalley. 2014. Can an engineering summer bridge program effectively transition underrepresented minority students leading to increased student success. In ASEE Annual Conference, Indianapolis, IN. https://peer. asee. org/20142.

[16] Ron Eglash, Mukkai Krishnamoorthy, Jason Sanchez, and Andrew Woodbridge. 2011. Fractal simulations of African design in pre-college computing education. ACM Transactions on Computing Education (TOCE) 11, 3 (2011), 17.

[17] Marisa Exter. 2015. Entering the First Year of a Multi-disciplinary, Hands-on, Competency-Based Learning Experience: Hopes and concerns of students, parents and faculty. ASEE Annual Conference and Exposition 3, 16 (2015), 18-123.

[18] Jason Freeman, Brian Magerko, Tom McKlin, Mike Reilly, Justin Permar, Cameron Summers, and Eric Fruchter. 2014. Engaging underrepresented groups in high school introductory computing through computational remixing with EarSketch. In Proceedings of the 45th ACM technical symposium on Computer science education. ACM, 85-90.

[19] Stacy Holander Gleixner. 2013. EXCEED: Excellence in Your Engineering Education Summer Transition Program. age 23 (2013), 1

[20] Joanna Goode and Jane Margolis. 2011. Exploring computer science: A case study of school reform. ACM Transactions on Computing Education (TOCE) 11, 2 (2011), 12.

[21] Mark Guzdial, Barbara J Ericson, Tom McKlin, and Shelly Engelman. 2012. A statewide survey on computing education pathways and influences: factors in broadening participation in computing. In Proceedings of the ninth annual international conference on International computing education research. ACM, 143-150.

[22] Rashina Hoda and Peter Andreae. 2014. It's not them, it's us! Why computer science fails to impress many first years. In Proceedings of the Sixteenth Australasian Computing Education Conference-Volume 148. Australian Computer Society, Inc., $159-162$

[23] Stephen Hutt, Margo Gardener, Donald Kamentz, Angela L Duckworth, and Sidney K D'Mello. 2018. Prospectively predicting 4-year college graduation from student applications. In Proceedings of the 8th International Conference on Learning Analytics and Knowledge. ACM, 280-289.

[24] Divya Jindal-Snape and Bart Rienties. 2016. Multi-dimensional transitions of international students to higher education. Routledge.

[25] Summer Dann Johnson, Paige Davis, Ashley Elisabeth Thibodeaux, Laura H Ikuma, Kelly A Rusch, and Warren N Waggenspack Jr. 2011. Peer Mentoring, A Transition Program to Improve Retention in the College of Engineering. In American Society for Engineering Education. American Society for Engineering Education.

[26] Richard Ladner and Tammy VanDeGrift. 2011. Introduction to special issue (part 1): Broadening participation in computing education. ACM Transactions on Computing Education (TOCE) 11, 2 (2011), 6.

[27] Richard Ladner and Tammy VanDeGrift. 2011. Special issue on broadening participation in computing education (part 2). ACM Transactions on Computing Education (TOCE) 11, 3 (2011), 13.

[28] Colleen M Lewis. 2017. ACM RETENTION COMMITTEE Twelve tips for creating a culture that supports all students in computing. ACM Inroads 8, 4 (2017), 17-20.

[29] Houston Lowe and Anthony Cook. 2003. Mind the gap: are students prepared for higher education? Journal of further and higher education 27, 1 (2003), 53-76.

[30] Rachel E Maunder, Matthew Cunliffe, Jessica Galvin, Sibulele Mjali, and Jenine Rogers. 2013. Listening to student voices: student researchers exploring undergraduate experiences of university transition. Higher Education 66, 2 (2013), 139-152.

[31] Venicia McGhie. 2017. Entering university studies: identifying enabling factors for a successful transition from school to university. Higher Education 73, 3 (2017), $407-422$

[32] Craig McInnis. 2001. Researching the first year experience: where to from here? Higher Education Research \& Development 20, 2 (2001), 105-114.

[33] Tsubasa Morioka, Nicole B Ellison, and Michael Brown. 2016. Identity work on social media sites: Disadvantaged students' college transition processes. In Proceedings of the 19th ACM conference on computer-supported cooperative work \& social computing. ACM, 848-859.

[34] Krista L Nelson, Danielle N Newman, Janelle R McDaniel, and Walter C Buboltz. 2013. Gender differences in fear of failure amongst engineering students. International Journal of Humanities and Social Science 3, 16 (2013), 10-16.

[35] Jacob D Pleitz, Alexandra E MacDougall, Robert A Terry, M Ronald Buckley, and Nicole J Campbell. 2015. Great expectations: Examining the discrepancy between expectations and experiences on college student retention. Fournal of College Student Retention: Research, Theory \& Practice 17, 1 (2015), 88-104.

[36] Debra J Richardson 2018. ACM RETENTION COMMITTEE Student-focused initiatives for retaining students in computing programs. ACM Inroads 9, 2 (2018), $13-18$

[37] Madeleine R. H. Roberts, Tanya J. McGill, and Peter N. Hyland. 2012. Attrition from Australian ICT Degrees: Why Women Leave. In Proceedings of the Fourteenth Australasian Computing Education Conference - Volume 123 (ACE '12). Australian Computer Society, Inc., Darlinghurst, Australia, Australia, 15-24. http://dl.acm. org/citation.cfm?id=2483716.2483719 
[38] Shannon Rodgers, Brittany Maloney, Bernd Ploderer, and Margot Brereton. 2016. Managing Stress, Sleep and Technologies: An Exploratory Study of Australian University Students. In Proceedings of the 28th Australian Conference on ComputerHuman Interaction (OzCHI '16). ACM, New York, NY, USA, 526-530. https: //doi.org/10.1145/3010915.3010961

[39] Mary Beth Rosson, John M Carroll, and Hansa Sinha. 2011. Orientation of undergraduates toward careers in the computer and information sciences: Gender, self-efficacy and social support. ACM Transactions on Computing Education (TOCE) 11, 3 (2011), 14.

[40] Noah Salzman, Matthew W Ohland, and Monica E Cardella. 2017. Developing an Instrument to Assess the Effects of Pre-College Engineering Participation on the Experiences of First-Year Engineering Students. (2017).

[41] Elaine Seymour, Nancy M Hewitt, and Cynthia M Friend. 1997. Talking about leaving: Why undergraduates leave the sciences. Vol. 12. Westview press Boulder, $\mathrm{CO}$

[42] Angela A. Siegel and Mark Zarb. 2016. Student Concerns Regarding Transition into Higher Education CS. In Proceedings of the 2016 ACM Conference on Innovation and Technology in Computer Science Education (ITiCSE '16). ACM, New York, NY, USA, 23-28. https://doi.org/10.1145/2899415.2909581

[43] Madeline E Smith. 2014. Connecting students and families for support during the college transition. In Proceedings of the companion publication of the 17th ACM conference on Computer supported cooperative work \& social computing. ACM, 93-96.

[44] A. Leyf Peirce Starling and Diane Brauner. 2016. Engaging Students with Visual Impairments or Blindness through Comprehensive and Accessible Engineering Experiences. Presented at K-12 \& Pre-College Engineering Division Poster Session: Works in Progress. American Society for Engineering Education 3, 16 (2016), $10-16$

[45] V Tinto. 1993. A theory of individual departure from institutions of higher education. Leaving college: Rethinking the causes and cures of student attrition (1993), 84-137.

[46] Elsa Q Villa. 2018. ACM RETENTION COMMITTEE Minority voices: interrupting the social environment to retain undergraduates in computing. ACM Inroads 9, 3 (2018), 31-33.

[47] Henry M Walker. 2017. Retention of students in introductory computing courses: preliminary plans-ACM retention committee. ACM Inroads 8, 4 (2017), 12-12.

[48] OJ Webb and DRE Cotton. 2018. Early withdrawal from higher education: a focus on academic experiences. Teaching in Higher Education (2018), 1-18.

[49] Mark Zarb and Angela A Siegel. 2017. An Analysis of Pupil Concerns Regarding Transition into Higher Education. In Researcher Links Workshop: Higher Education for All. 3-16.

[50] Ms. Elaine Zundl. 2015. Understanding the Relationship between Living-Learning Communities and Self-Efficacy of Women in Engineering. ASEE Annual Conference and Exposition 3, 16 (2015), 18-123.

\section{APPENDIX A: THE SURVEY}

This survey has been written by an international team of researchers in Computer Science Education looking at concerns that students have when transitioning to university/collegiate life. To help us better prepare our students for life at university/collegiate life, please complete this anonymous survey about concerns that you may have had as you entered university/college. We expect the survey will take around 10-15 minutes to complete. We are collecting no information that would identify you, and your responses will be completely anonymous.

Your participation in the survey is entirely voluntary. You can withdraw at any time. Simply close this window to stop participating. There are no negative implications for you doing so.

The data resulting from this survey will only be used for analysis and reporting of aggregated results.

This study has been granted ethical approval. The questionnaire is being deployed in a number of locations internationally. You are free to discuss your participation in this study with the lead researcher.

Thank you for your help.

\section{Introduction}

- List your University/College
- Select Your Country: UK, USA, Ghana, Sweden, Canada, Other...

- Select Your Gender: Male, Female, Undecided, Non-Traditional, Prefer Not To Say, Other...

\section{Quantitative Questions}

Each of the questions below was set to a 5-point Likert scale, ranging from Major Concern to No Concern. A Not Applicable option was also presented.

Housing Concerns. For each of the following areas, please let us know how these areas of concern applied to you when you started college/university:

- Finding/quality of housing (including additional items such as meal plans, etc.)

- Having to live with flatmates/roommates

Money Concerns. For each of the following areas, please let us know how these areas of concern applied to you when you started college/university:

- General money concerns

- Housing costs

- Tuition fees/course fees

- Applying for scholarships/funding

Course Concerns. For each of the following areas, please let us know how these areas of concern applied to you when you started college/university:

- Choosing the right courses

- Workload expectation

- Managing my time well

- Liking the course

- Being good at the course

- Feeling prepared

- The possibility of failing, and any repercussions

Lecturer/Professor Concerns. For each of the following areas, please let us know how these areas of concern applied to you when you started college/university:

- Level of friendliness

- Willingness/availability to help

- Level of interest of the class/topic

Study Experience Concerns. For each of the following areas, please let us know how these areas of concern applied to you when you started college/university:

- Class size (too big/small)

- City size and location

- Different learning environments (e.g. lecture halls, exercise rooms, labs, ..)

Accessibility Concerns. For each of the following areas, please let us know how these areas of concern applied to you when you started college/university. Accessibility issues include requesting support (e.g. "will I get support with my dyslexia?"), or concerns about navigating the environment (e.g. "can I get my wheelchair to class?"). If you do not have any accessibility issues, please tick the Not Applicable box.: 
- Adequate accessibility support

Social Concerns. For each of the following areas, please let us know how these areas of concern applied to you when you started college/university:

- Ability to make friends

- Peer pressure

- Feeling like an outsider

Homesickness Concerns. For each of the following areas, please let us know how these areas of concern applied to you when you started college/university:

- Missing my friends/family/pets

- Distance from home
- Ability to go home

- Frequency of going home

\section{Qualitative Questions}

What were your thoughts when you started College/University? Please fill these in English where possible.

- When I started college/university, I was looking forward to...

- From home/school, I thought I would miss...

- When I started college/university, I hoped I would find...

- When I started college/university, I worried about..

- When I started college/university, I expected...

- Any other comments? 